U.S. DEPARTMENT OF THE INTERIOR

U.S. GEOLOGICAL SURVEY

\title{
DATA REPORT FOR ONSHORE-OFFSHORE WIDE-ANGLE SEISMIC RECORDINGS IN THE BERING-CHUKCHI SEA, WESTERN ALASKA AND EASTERN SIBERIA
}

By

Thomas M. Brocher ${ }^{1}$, Richard M. Allen ${ }^{2}$, David B. Stone ${ }^{3}$, Lorraine W. Wolf ${ }^{4}$ and Brian K. Galloway 5

Open-File Report 95-650

1345 Middlefield Road, M/S 977, Menlo Park, CA 94025

2Dept. of Geological Sciences, University of Durham, South Road, Durham, DH1 3LE, U.K.

${ }^{3}$ Geophysical Institute, 903 Koyukuk Dr., University of Alaska, Fairbanks, AK 99775-0800

${ }^{4}$ Department of Geology, 210 Petrie Hall, Auburn University, Auburn, AL 36849

5 Dept. of Geophysics, Stanford University, Stanford, CA 94305

This report is preliminary and has not been reviewed for conformity with U.S. Geological Survey editorial standards or with the North American Stratigraphic Code. Any use of trade, product or firm names is for descriptive purposes only and does not imply endorsement by the U.S. Government.

Menlo Park, California 


\begin{abstract}
This report presents fourteen deep-crustal wide-angle seismic reflection and refraction profiles recorded onland in western Alaska and eastern Siberia from marine air gun sources in the Bering-Chukchi Seas. During a 20-day period in August, 1994, the R/V Ewing acquired two long (a total of $3754 \mathrm{~km}$ ) deep-crustal seismic-reflection profiles on the continental shelf of the Bering and Chukchi Seas, in a collaborative project between Stanford University and the United States Geological Survey (USGS). The Ewing's 137.7 liter (8355 cu. in.) air gun array was the source for both the multichannel reflection and the wide-angle seismic data. The Ewing, operated by the Lamont-Doherty Earth Observatory, steamed northward from Nunivak Island to Barrow, and returned, firing the air gun array at intervals of either $50 \mathrm{~m}$ or $75 \mathrm{~m}$. About 37,700 air gun shots were fired along the northward directed Lines 1 and 2, and more than 40,000 air gun shots were fired along the southward directed Line 3. The USGS and the University of Alaska, Fairbanks (UAF), deployed an array of twelve 3-component REFTEK and PDAS recorders in western Alaska and eastern Siberia which continuously recorded the air gun signals fired during the northward bound Lines 1 and 2 . Seven of these recorders also continuously recorded the southward bound Line 3. These wide-angle seismic data were acquired to: (1) image reflectors in the upper to lower crust, (2) determine crustal and upper mantle refraction velocities, and (3) provide important constraints on the geometry of the Moho along the seismic lines. In this report, we describe the land recording of wide-angle data conducted by the USGS and the UAF, describe in detail how the wide-angle REFTEK and PDAS data were reduced to common receiver gather seismic sections, and illustrate the wide-angle seismic data obtained by the REFTEKs and PDAS's. Air gun signals were observed to ranges in excess of $400 \mathrm{~km}$, and crustal and upper :mantle refractions indicate substantial variation in the crustal thickness along the transect.
\end{abstract}




\section{CONTENTS}

$\begin{array}{lr}\text { Abstract } & 1 \\ \text { Introduction } & 3 \\ \text { Data Acquisition } & 5 \\ \text { Data Reduction } & 12 \\ \text { Description of the Data } & 12 \\ \text { Acknowledgments } & 17 \\ \text { References } & 18 \\ \text { Appendix 1. R/V Ewing Airgun Firing Times and Locations } & 19 \\ \text { Appendix 2. Converting Reftek Format Data To Receiver Gathers } & 24 \\ \text { Appendix 3. ProMAX Input and Processing Parameters } & 28 \\ \text { Appendix 4. PASSCAL SEGY Trace Header Format } & 35\end{array}$

\section{FIGURES}

Figure 1. Map of Chukchi-Bering Sea showing location of seismic lines and stations

Figure 2. Geologic map of Chukchi-Bering Sea showing seismic lines and stations

Figure 3. Detail map of Chukchi-Bering Sea showing seismic lines and stations 39

$\begin{array}{ll}\text { Figure 4. R/V Ewing air gun deployment diagram } & 40\end{array}$

Figure 5. Detail of 20-element air gun array towed from R/V Ewing 41

Figure 6. Receiver gather from station Lietnik for line 1

Figure 7. Receiver gather from station Provideniya for line 1

Figure 8. Receiver gather from station Novoye Chaplino for line 1

Figure 9. Receiver gather from station Tin City for line 1 45

Figure 10. Receiver gather from station Little Diomede Island for line 1

Figure 11. Receiver gather from station Point Hope for line 1 47

Figure 12. Receiver gather from station Cape Lisbourne for line 1

Figure 13. Receiver gather from station Point Lay for lines 1 and $2 \quad 49$

Figure 14. Receiver gather from station Point Lay for line $3 \quad 50$

Figure 15. Receiver gather from station Tin City for line $3 \quad 51$

Figure 16. Receiver gather from station Novoye Chaplino for line $3 \quad 52$

Figure 17. Receiver gather from station Provideniya for line $3 \quad 53$

Figure 18. Receiver gather from station Provideniya, Guralp for line $3 \quad 54$

Figure 19. Receiver gather from station Gambell for line $3 \quad 55$

Figure 20. Ray coverage obtained during wide-angle recording 56

Figure 21. Weather data obtained during wide-angle recording 57

\section{TABLES}

Table 1. R/V Ewing seismic-reflection line endpoints 9

Table 2. Sonobuoy Launch Times and Locations 10

Table 3. Wide-angle station locations and elevations 11 


\section{INTRODUCTICN}

The Bering Shelf-Chukchi Sea region comprises over half of the total continental shelf area of the United States of America, and forms part of the vast system of continental shelves that encircle the Arctic Ocean and link the Alaskan and Russian mainlands. In August, 1994, two long north-south trending deep-crustal seismic-reflection profiles were acquired in the Bering and Chukchi seas (Figure 1) in a collaborative project between Stanford University and the United States Geological Survey (USGS) (Galloway and Shipboard Scientific Party, EW94-10, unpublished manuscript, 1994; Galloway et al., 1994). These seismic lines are approximately perpendicular to several major structural features including the foreland (Arctic Platform), the foldthrust belt (Colville Basin and Brooks Range), a region of possible late-to post-orogenic collapse (Seward and Chukotshiy), the accreted terranes of the Bering Shelf "collage", and the abandoned subduction zone (Beringian margin). In addition, the seismic lines imaged the deep-crustal structure beneath several major sedimentary basins developed across these various tectonic belts. The transect was designed to provide another deep-crustal transect of the North American continent from ocean basin to ocean basin, similar to the Trans-Alaska Crustal Transect (TACT), which ran from the northern Gulf of Alaska to the North Slope, following the Alaskan Highway .

Parts of the transect were selected to (1) specifically address the nature of the boundaries or transition between segments of the orogenic belt with different known histories, (2) couple surface studies with seismic imaging of the deep crust in order to study better the magmatic and tectonic processes that shape continental crust at depth beneath orogenic belts, and (3) image key structures in the crust and mantle that accommodated significant shortening or extension between Eurasia and North America in the Cretaceous and Tertiary. Deep-crustal seismic-reflection profiling was conducted using a 20-element 137.7 liter (8355 cu. in.) air gun array and a 4.2-km-long digital streamer towed by the R/V Ewing on leg EW94-10.

Additional reasons for choosing the general location of the seismic reflection lines included crossing perpendicular (or as closely as possible) to major structures, to be close to the coast to 
facilitate geological correlation and to allow in-line wide-angle recording (Figure 2), to tie to COST wells and accessible industry seismic grids, to remain in water deep enough for the Ewing to . work safely in the ice-free near-coastal waters of the Beaufort Sea and to remain outside the 3-mile limit whilst in U.S. waters in order to be exclusively in Federal waters which simplified permitting issues with respect to marine mammals.

During a 20-day period in August, the Ewing acquired two long (a total of $3754 \mathrm{~km}$ ) deep-crustal seismic-reflection profiles. The profiles started in the south at the July 1994 Ewing seismic-reflection survey of the Aleutiah Island and Bering Sea (McGeary et al., 1994) in the vicinity of Nunivak Island (Figure 1), traversed northward to the east of Saint Lawrence Island, across the Norton Basin, through the Bering Straits, across the Hope Basin, hugged the coastline as it crosses the Herald Arch, Brooks Range Orogen and Colville Foredeep, and finished at the shelf edge of the Canada Basin. A parallel profile to the west returned through the Bering Straits, hugged the International Border east of the Chukotshiy Peninsula, passed just west of Saint Lawrence Island and across the Navarin Basin tying to the Navarin Basin COST well, ending oceanward of the Cretaceous Beringian margin. The Ewing fired the air gun array along these profiles at intervals of 50 or $75 \mathrm{~m}$. About 37,700 air gun shots were fired along the northward directed Lines 1 and 2, and more than 40,000 air gun shots were fired along the southward directed Line 3.

We describe the acquisition and reduction of the wide-angle seismic data recorded onshore in western Alaska and eastern Siberia during this seismic reflection transect. The USGS deployed an array of eight three-component REFTEK recorders in western Alaska which continuously recorded the air gun signals fired during northward-bound Lines 1 and 2 (Figure 3). Three REFTEK recorders also continuously recorded the return profile Line 3 . In addition, the UAF deployed four recorders in the Chukotshiy Peninsula, eastern Siberia, which recorded both Lines 1 and 3. The recordings, made at an average interval of about $150 \mathrm{~km}$ along the western shore of Alaska and Siberia, were designed to provide reconnaissance-level seismic refraction information about average crustal velocities and thicknesses along the seismic reflection profiles. 


\section{DATA ACQUISITION}

\section{R/V Ewing Instrumentation and Operations}

The R/V Ewing acquired marine reflection profiles with a $50 \mathrm{~m}$ (sometimes altered to 75 m) shot-spacing (40 or 27 fold) and record lengths between 16 and 23 seconds. Principal instrumentation included a 4.2-km, 160-channel digital streamer and a 137.7 liter (8355 cu. in.), 20-chamber air gun source (Galloway and Shipboard Scientific Party, EW94-10, unpublished manuscript, 1994; Galloway et al., 1994). The ship's schedule was chosen to maximize the chances of being able to extend the seismic lines northwards over the rifted passive margin into the Canada Basin during optimal sea ice conditions. Water depths were generally between 25 and 50 $\mathrm{m}$ for most of the cruise, deepening only at both ends of the lines.

The northbound leg (Lines 1 and 2) started at 2220 Local time (L) Monday August 8th (Julian Day (JD) 220 at 0620 Universal Coordinated Time (UCT)) and reached the northern end of the survey at 0645L Thursday August 18th (JD 2301445 UCT). The southbound leg (Line 3) ended at 1700L Tuesday August 30th (JD 243 at 0100 UCT). Together both legs yielded about $3754 \mathrm{~km}$ of multichannel seismic-reflection data. Table 1 presents the latitude, longitude, and time of the starting and end points of each of the reflection line segments acquired during the survey. Note that Line 1 was composed of seven segments (a, c-h), Line 2 consists of 5 segments (a-e), and Line 3 consists of six segments (a-f). These tracks represented all the pre-cruise plans apart from the optimistic northerly extensions into the Chukchi Sea (prevented by pack ice), and work in Russian waters (replaced by sub-parallel lines on the US side of the Convention Line).

The geometry of the air gun deployment from the $\mathbf{R} / \mathbf{V}$ Ewing is presented in Figures 4 and 5. The air gun array, composed of Bolt air guns, was generally towed at depths between 8 and 10 meters. Eight guns were towed on each side of the ship from large retractable booms that are swung out abeam of the ship (Figure 4). The remaining four air guns were deployed from an A-frame on the stern of the ship. The ship-to-gun distances were staggered to minimize fouling the air guns and to optimally separate the air bubbles created by the air gun array: the center of the air 
gun array was towed approximately $39.6 \mathrm{~m}$ behind the stern of the ship (Figure 4 ). The width of the air gun array across the beam of the ship was roughly $33.8 \mathrm{~m}$ (111 feet) (Figure 5). The Magnavox Global Positioning Satellite (GPS) receiver for the ship was located above the ship's bridge about $47.8 \mathrm{~m}$ forward of the stern of the ship, roughly $87.4 \mathrm{~m}$ forward of the center of the air gun array. The source-receiver ranges placed in the trace headers were not corrected for this minor offset between the air gun array and GPS receiver. The sizes of the air gun chambers were varied from 2.4 liter $(145 \mathrm{cu}$. in.) to 14.2 liter $(850 \mathrm{cu}$. in.) to provide a tuned outgoing source wavelet.

Air gun shot times recorded in the navigation files represent the air gun fire command time determined from a Magnavox GPS clock. These shot times are considered accurate to within a millisecond. Files containing smoothed navigation and shot times were transmitted daily from the Ewing via e-mail.

Approximately 44 sonobuoys were deployed from the Ewing during the cruise (Galloway and Shipboard Scientific Party, EW94-10, unpublished manuscript, 1994). These were expendable military sonobuoys which self-scuttled after 8 hours. Table 2 summarizes the launch times and locations of the sonobuoys; they were launched every 6 hours at the start of the cruise and every 12 hours later on in the cruise. Additional geophysical data acquired during the cruise included gravity, magnetics, and $3.5 \mathrm{kHz}$ bathymetry (Galloway and Shipboard Scientific Party, EW94-10, unpublished manuscript, 1994). Weather data were also continuously recorded on the Ewing.

\section{Wide-Angle Recording}

The USGS deployed eight 3-component REFTEK recorders on the western coast of Alaska between St. Lawrence Island and Point Lay (Figure 1) during the Ewing cruise (stations 1-8). The station sites were chosen based on: (1) their proximity to the seismic reflection lines, (2) the ability to reach the site via charter aircraft, and (3) the desire to obtain deep-crustal information between St. Lawrence Island and Cape Lisburne (Figure 3). Little Diomede Island, King Island, 
and the Northeast Cape on St. Lawrence Island are all located in the Bering Strait and northern Bering Shelf, and all are located directly on the seismic lines, to try to record arrivals reflected from the middle to lower crust. We recorded three-component seismometers to improve our chances of recording converted shear-wave arrivals.

The station sites were generally reached via fixed wing aircraft, although the stations at Little Diomede and King Islands were reached by helicopter. The REFTEK stations were generally located close to landing strips. Instruments were housed in plastic containers and buried as much as possible to minimize disruption by wildlife. All cabling was buried wherever possible. Roughly half of the instruments were left recording when deployed, the other half were programmed to turn on at a later time. Four of the sites were located on islands in the Bering Straits/Sea, and four were located on the western Alaskan coast. Table 3 provides a list of the stations, their locations and elevations, and indicates when they were each deployed and retrieved. Station latitudes and longitudes in Table 3 represent averages from 8-days of recording GPS data on the hour. Estimated uncertainties of the station latitudes and longitudes are generally less than $40 \mathrm{~m}$. Station elevations were determined from USGS topographic maps once the horizontal locations were fixed by GPS. The eight sites were used to record signals generated along Lines 1 and 2. Two recorders were redeployed at Gambell and Tin City to record Line 3.

Poor flying conditions between August 10 and August 16 (JD 222-229) made it impossible to retrieve any REFTEK stations during that week, but ultimately did not lead to any loss of data. Stations were deployed to the north and south of the base station at Nome, Alaska, using a combination of fixed wing and helicopter charter aircraft.

The digital REFTEK recorders deployed (primarily models 07G) consist of four major components (PASSCAL, 1991). These components include the (1) Data Acquisition System (DAS), (2) internal hard disk drive, (3) internal GPS Clock, and (4) 3-component 4.5- $\mathrm{Hz}$ seismometers. For continuous recording it was necessary to supplement a small internal battery with an external 12-V truck battery. Each REFTEK DAS was controlled by a Hand Held Terminal (HHT), which was used to program the DAS, determining such parameters as the start and end 
times of recording, the sample rate ( $100 \mathrm{~Hz}$ in our case), mode of recording (continuous in our case), and number of channels to record ( 3 in our case). The GPS receiver clocks had a duty cycle of 5 minutes per hour. Recording was performed at $10 \mathrm{msec}$ sample rate in compressed REFTEK data format.

The University of Alaska, Fairbanks (UAF), with Russian collaborators, deployed four additional stations on the eastern shore of the Chukotshiy Peninsula in Russia (Table 3). The digital recorders deployed by the UAF group in Russia were all Teledyne PDAS units. The data were recorded on external SCSI hard drives, and a sampling rate of $50 \mathrm{~Hz}$ was used. Stations at Novoye Chaplino, Lavrentiya, and a station at Provideniya used 3-component L22 seismometers. Another station at Provideniya recorded a Guralp broad-band seismometer. The two Provideniya stations and the Novoye Chaplino station ran continuously for at least two days before and after the closest approach of the Ewing. The Lavrentiya station shut itself down at irregular intervals and did not write data to the external SCSI drive. The data that were collected are presumably stored in the 8 Mbyte internal memory, but at the present time it is not possible to make the system boot.

All the PDAS's had GPS clocks that checked the timing every hour. The GPS clocks also allowed the stations to be located accurately with respect to latitude and longitude. The altitude for the two Provideniya sites were obtained using a hand held Garmin GPS receiver. The altitude of the Novoye Chaplino site was estimated visually since it was only about $2 \mathrm{~m}$ above sea level and within about $200 \mathrm{~m}$ of the coastline. GPS position information for Lavrentiya is locked up in the internal memory, and the position quoted in Table 3 is based on local maps, whilst altitude was estimated visually compared with the nearby estuary.

A second station was operated at Provideniya using a Guralp 40T broad band instrument. Because of limited memory, this instrument was run in event-detect mode for the northbound legs of the Ewing, but was run in continuous mode for the time of passage of the Ewing on its southbound leg. 
TABLE 1. R/V Ewing Seismic Reflection Line Endpoints

\begin{tabular}{|c|c|c|c|}
\hline $\begin{array}{c}\text { UCT } \\
\text { Day:HR:MIN:SEC }\end{array}$ & $\begin{array}{l}\text { Lat. }(\mathrm{N}) \\
\text { Deg. Minute }\end{array}$ & $\begin{array}{l}\text { Long. (W) } \\
\text { Deg. Minute }\end{array}$ & $\begin{array}{l}\text { Line } \\
\text { No. }\end{array}$ \\
\hline $\begin{array}{l}220: 00: 00: 13.766 \\
220: 03: 48: 53.934\end{array}$ & $\begin{array}{ll}58 & 57.4170 \\
58 & 47.7070\end{array}$ & $\begin{array}{l}16931.0150 \\
16935.8248\end{array}$ & $\begin{array}{l}\text { test } 25 \\
\text { test25 }\end{array}$ \\
\hline $\begin{array}{l}220: 06: 20: 01.186 \\
221: 03: 16: 49.460\end{array}$ & $\begin{array}{ll}58 & 47.5825 \\
60 & 22.0099\end{array}$ & $\begin{array}{l}16932.4891 \\
16909.7851\end{array}$ & $\begin{array}{l}1 \mathrm{a} \\
1 \mathrm{a}\end{array}$ \\
\hline $\begin{array}{l}221: 05: 56: 34.279 \\
221: 17: 35: 53.892\end{array}$ & $\begin{array}{ll}60 & 20.4038 \\
61 & 20.6420\end{array}$ & $\begin{array}{l}16910.0437 \\
16855.0994\end{array}$ & $\begin{array}{l}1 \mathrm{c} \\
1 \mathrm{c}\end{array}$ \\
\hline $\begin{array}{l}221: 17: 36: 56.059 \\
223: 14: 35: 49.868\end{array}$ & $\begin{array}{ll}61 & 20.7396 \\
62 & 10.2248\end{array}$ & $\begin{array}{l}16855.0821 \\
16842.8187\end{array}$ & $\begin{array}{l}\text { ld } \\
\text { ld }\end{array}$ \\
\hline $\begin{array}{l}223: 14: 49: 09.875 \\
225: 06: 49: 31.684\end{array}$ & $\begin{array}{ll}62 & 11.1615 \\
65 & 26.4702\end{array}$ & $\begin{array}{l}16842.5296 \\
168 \quad 19.6007\end{array}$ & $\begin{array}{l}1 \mathrm{e} \\
1 \mathrm{e}\end{array}$ \\
\hline $\begin{array}{l}225: 06: 50: 03.443 \\
225: 19: 44: 26.998\end{array}$ & $\begin{array}{l}6526.5177 \\
6642.2436\end{array}$ & $\begin{array}{ll}168 & 19.6006 \\
168 & 02.8101\end{array}$ & $\begin{array}{l}\text { lf } \\
\text { lf }\end{array}$ \\
\hline $\begin{array}{l}225: 19: 44: 38.981 \\
226: 01: 20: 44.826\end{array}$ & $\begin{array}{l}6642.2613 \\
6709.4709\end{array}$ & $\begin{array}{ll}168 & 02.8008 \\
167 & 53.5477\end{array}$ & $\begin{array}{l}\lg \\
\lg \end{array}$ \\
\hline $\begin{array}{l}226: 01: 20: 54.058 \\
229: 01: 39: 42.797\end{array}$ & $\begin{array}{l}6709.4825 \\
7029.6770\end{array}$ & $\begin{array}{l}16753.5457 \\
16301.1523\end{array}$ & $\begin{array}{l}1 \mathrm{~h} \\
1 \mathrm{~h}\end{array}$ \\
\hline $\begin{array}{l}229: 02: 06: 29.019 \\
229: 04: 46: 27.863\end{array}$ & $\begin{array}{l}7030.6319 \\
7034.9162\end{array}$ & $\begin{array}{l}16255.6997 \\
16235.7926\end{array}$ & $\begin{array}{l}2 a \\
2 a\end{array}$ \\
\hline $\begin{array}{l}\text { 229:04:50:24.790 } \\
\text { 229:05:46:14.549 }\end{array}$ & $\begin{array}{l}7034.8438 \\
7033.4930\end{array}$ & $\begin{array}{l}16236.6105 \\
16248.2117\end{array}$ & $\begin{array}{l}2 b \\
2 b\end{array}$ \\
\hline $\begin{array}{l}229: 05: 54: 04.903 \\
229: 18: 07: 47.453\end{array}$ & $\begin{array}{l}7033.2420 \\
7050.6397\end{array}$ & $\begin{array}{ll}162 & 49.7473 \\
160 & 11.2175\end{array}$ & $\begin{array}{l}2 \mathrm{c} \\
2 \mathrm{c}\end{array}$ \\
\hline $\begin{array}{l}229: 18: 10: 58.606 \\
230: 06: 12: 59.665\end{array}$ & $\begin{array}{ll}70 & 50.7305 \\
71 & 23.6895\end{array}$ & $\begin{array}{l}16010.4242 \\
157 \quad 06.7564\end{array}$ & $\begin{array}{l}2 d \\
2 d\end{array}$ \\
\hline $\begin{array}{l}230: 06: 13: 33.151 \\
230: 15: 51: 30.082\end{array}$ & $\begin{array}{ll}71 & 23.7190 \\
71 & 47.2073\end{array}$ & $\begin{array}{l}15706.6012 \\
154 \quad 17.1128\end{array}$ & $\begin{array}{l}2 \mathrm{e} \\
2 \mathrm{e}\end{array}$ \\
\hline $\begin{array}{l}\text { 232:08:52:15.116 } \\
\text { 233:04:45:30.128 }\end{array}$ & $\begin{array}{ll}71 & 23.2144 \\
70 & 30.9559\end{array}$ & $\begin{array}{l}16259.6374 \\
16642.1906\end{array}$ & $\begin{array}{l}3 \mathrm{a} \\
3 \mathrm{a}\end{array}$ \\
\hline $\begin{array}{l}\text { 233:04:46:12.271 } \\
\text { 236:06:01:01.869 }\end{array}$ & $\begin{array}{l}7030.9238 \\
6532.3711\end{array}$ & $\begin{array}{l}16642.3021 \\
16850.1773\end{array}$ & $\begin{array}{l}3 \mathrm{~b} \\
3 \mathrm{~b}\end{array}$ \\
\hline $\begin{array}{l}236: 06: 01: 37.237 \\
236: 08: 33: 48.244\end{array}$ & $\begin{array}{l}6532.3286 \\
6536.9222\end{array}$ & $\begin{array}{l}16850.1736 \\
16848.4346\end{array}$ & $\begin{array}{l}3 c \\
3 c\end{array}$ \\
\hline $\begin{array}{l}236: 08: 34: 40.904 \\
240: 23: 59: 45.445\end{array}$ & $\begin{array}{ll}65 & 36.8564 \\
58 & 41.4294\end{array}$ & $\begin{array}{l}16848.4057 \\
17749.9741\end{array}$ & $\begin{array}{l}3 d \\
3 d\end{array}$ \\
\hline
\end{tabular}


TABLE 2. Sonobuoy Launch Times and Locations

\begin{tabular}{|c|c|c|c|c|}
\hline $\begin{array}{l}\text { Sono- } \\
\text { buoy } \\
\text { No. }\end{array}$ & Line, FFID* & $\begin{array}{l}\text { Launch Time } \\
\text { JD:Hr:Mn:Second }\end{array}$ & $\begin{array}{l}\text { Latitude (N) } \\
\text { Deg. Minute }\end{array}$ & $\begin{array}{l}\text { Longitude (W) } \\
\text { Deg. Minute }\end{array}$ \\
\hline 46 & 2754 & $220: 23: 05: 53.027$ & 6002.6129 & 16914.6611 \\
\hline 47 & $1 \mathrm{C}$ & 221:06:56:10.223 & 6025.5245 & 16908.9543 \\
\hline 48 & 1331 & $221: 12: 29: 12.483$ & 6053.4262 & 16902.1449 \\
\hline 49 & $1 \mathrm{D}$ & 221:18:04:29.205 & 6123.3408 & 16854.3576 \\
\hline 50 & $1 \mathrm{D}$ & $221: 22: 22: 13.713$ & 6147.1694 & 16848.5531 \\
\hline 51 & 1874 & 222:06:41:46.194 & 6231.8642 & 16836.8780 \\
\hline 52 & $1 \mathrm{E}$ & $223: 19: 29: 46.560$ & 6232.7838 & 16836.6422 \\
\hline 53 & 556 & $223: 19: 37: 57.213$ & 6233.4572 & 16836.4720 \\
\hline 54 & 1793 & 224:05:33:22.191 & 6322.6162 & 16825.3647 \\
\hline 56 & 3242 & $224: 18: 01: 35.740$ & 6420.4298 & 16822.5858 \\
\hline 57 & 3873 & $224: 22: 56: 53.750$ & 6445.6120 & 16821.1411 \\
\hline 59 & 4659 & $225: 05: 01: 50.920$ & 6516.9759 & 16819.5657 \\
\hline 60 & 1067 & $225: 13: 05: 10.331$ & 6605.2475 & 16815.2221 \\
\hline 61 & 1901 & $225: 19: 00: 30.420$ & 6638.2316 & 16804.1369 \\
\hline 62 & $1 \mathrm{H}, \quad 3249$ & $226: 20: 17: 45.963$ & 6653.0658 & 16759.1615 \\
\hline 63 & $1 \mathrm{H}, 4525$ & $227: 03: 38: 27.235$ & 6726.7191 & 16747.5404 \\
\hline 64 & $1 \mathrm{H}, \quad 5218$ & $227: 07: 33: 14.440$ & 6744.9814 & 16741.0680 \\
\hline 65 & $1 \mathrm{H}, \quad 6062$ & $227: 12: 24: 33.189$ & 6806.8259 & 16728.6702 \\
\hline 66 & $1 \mathrm{H}, \quad 7027$ & $227: 17: 51: 36.006$ & 6830.9059 & 16704.5035 \\
\hline 67 & $1 \mathrm{H}, \quad 7277$ & $227: 19: 14: 39.265$ & 6837.1354 & 16658.3267 \\
\hline 68 & $1 \mathrm{H}, \quad 7520$ & $227: 20: 37: 32.723$ & 6843.1411 & 16652.0148 \\
\hline 69 & $1 \mathrm{H}, \quad 9140$ & $228: 05: 58: 15.952$ & 6920.6415 & 16554.6541 \\
\hline 71 & $1 \mathrm{H}, 10070$ & $228: 11: 18: 19.003$ & 6940.8244 & 16513.7520 \\
\hline 72 & $2 \mathrm{~A}, \quad 122$ & $229: 02: 14: 08.902$ & 7030.8092 & 16254.0149 \\
\hline 73 & $2 \mathrm{D}, \quad 1222$ & $230: 02: 00: 00.318$ & 7111.6201 & 15808.0937 \\
\hline 74 & $3 \mathrm{~A}, \quad 1472$ & $232: 17: 00: 47.543$ & 7101.7400 & 16432.1451 \\
\hline 76 & $3 B, \quad 2726$ & $233: 20: 49: 52.719$ & 6943.0020 & 16850.3030 \\
\hline 77 & $3 \mathrm{~B}, 4051$ & $234: 04: 47: 07.493$ & 6907.8195 & 16849.8271 \\
\hline 78 & $3 B, 4236$ & 234:05:54:13.295 & 6902.8869 & 16850.1111 \\
\hline 79 & $3 B, 4597$ & 234:08:04:24.046 & 6853.2804 & 16849.7482 \\
\hline 80 & $3 B, 6630$ & $234: 20: 32: 11.795$ & 6759.2258 & 16849.8901 \\
\hline 81 & $3 \mathrm{D}$ & 236:13:42:16.699 & 6518.4330 & 16919.1057 \\
\hline 82 & $3 \mathrm{D}, 1561$ & 236:17:28:05.508 & 6505.7327 & 16943.8790 \\
\hline 83 & $3 \mathrm{D}, \quad 1729$ & $236: 18: 27: 36.503$ & 6502.3173 & 16950.6827 \\
\hline 84 & $3 \mathrm{D}, \quad 3730$ & 237:06:26:07.348 & 6421.3826 & 17110.2002 \\
\hline 85 & $3 \mathrm{D}, \quad 5234$ & $237: 15: 42: 54.094$ & 6349.8212 & 17206.3357 \\
\hline 86 & $3 \mathrm{D}, 5465$ & $237: 17: 05: 47.577$ & 6344.4311 & 17212.7717 \\
\hline 87 & $3 \mathrm{D}, 7583$ & $238: 05: 58: 43.443$ & 6254.7880 & 17312.3095 \\
\hline 88 & $3 \mathrm{D}, \quad 9499$ & $238: 17: 42: 27.788$ & 6209.8748 & 17404.4808 \\
\hline 90 & $3 \mathrm{D}, 11118$ & 239:03:37:02.365 & 6131.8635 & 17447.7129 \\
\hline 91 & $3 \mathrm{D}, 16638$ & $240: 13: 18: 57.810$ & 5922.3224 & 17708.2287 \\
\hline 92 & $3 \mathrm{D}, 18046$ & $240: 22: 00: 00.463$ & 5849.2104 & 17742.3537 \\
\hline 93 & $3 \mathrm{~F}, \quad 2511$ & $242: 16: 56: 59.889$ & 5826.8964 & 17531.2589 \\
\hline 94 & $3 F, \quad 3199$ & $242: 21: 05: 13.829$ & 5842.9563 & 17514.3087 \\
\hline
\end{tabular}

*Sonobuoy, line, and FFID numbers from Galloway and Shipboard Scientific Party, EW94-10 (unpublished manuscript, 1994). 
TABLE 3. REFTEK Station Locations and Elevations

\begin{tabular}{lllllrrl}
\hline $\begin{array}{l}\text { Station } \\
\text { No. }\end{array}$ & $\begin{array}{l}\text { Station } \\
\text { Name }\end{array}$ & $\begin{array}{l}\text { DAS } \\
\text { No. }\end{array}$ & $\begin{array}{l}\text { Latitude (N) } \\
\text { Deg. }\end{array}$ & $\begin{array}{l}\text { Longitude (W) } \\
\text { Deg. }\end{array}$ & $\begin{array}{l}\text { No. } \\
\text { GPS } \\
\text { Obs. }\end{array}$ & $\begin{array}{l}\text { Eleva- } \\
\text { tion } \\
\text { (m) }\end{array}$ & $\begin{array}{l}\text { lates and Times of } \\
\text { Deployment } \\
\text { (1994) }\end{array}$ \\
1 & Lietnik & 7279 & 63.322742 & 168.979082 & 242 & 5 & $219 / 2000-229 / 1900$ \\
2 & Gambell & 7282 & 63.771725 & 171.733129 & 223 & 2 & $219 / 2000-229 / 2000$ \\
3 & King Island & 7296 & 64.964777 & 168.057411 & 239 & 300 & $219 / 2000-229 / 2000$ \\
4 & Tin City & 7300 & 65.561635 & 167.924010 & 259 & 80 & $219 / 2000-231 / 0000$ \\
5 & Little Diomede & 7289 & 65.745256 & 168.925760 & 337 & 305 & $219 / 2000-233 / 2000$ \\
6 & Point Hope & 7281 & 68.353425 & 166.795966 & 288 & 1 & $221 / 2200-233 / 2000$ \\
7 & Cape Lisbourne & 7294 & 68.875000 & 166.113333 & 0 & 80 & $221 / 2300-233 / 1900$ \\
8 & Point Lay & 7301 & 69.730050 & 163.023758 & 285 & 2 & $222 / 0000-233 / 2000$ \\
9 & Lavrentiya\% & PDAS & 65.590 & 171.008 & & 3 & $225-230,234-238$ \\
10 & Novoye Chaplino\%P159 & 64.4958 & 172.8583 & & 2 & $218-240$ \\
11 & Provideniya\% & P180 & 64.4242 & 173.2324 & & 50 & $217-228,235-243$ \\
12 & Provideniya\% & Grlp & 64.4242 & 173.2324 & & 50 & $217-228,235-243$ \\
\hline
\end{tabular}

*REFTEK was programmed to record continuously from the time of deployment.

$\%$ Coordinates for stations at Provideniya and Novoye Chaplino are from GPS coordinates, coordinates for station at Lavrentiya are from a 1:200,000 Russian military topographic map.

Elevations for Russian stations are estimated from GPS for the two sites at Provideniya, from the nearby sea level for Novoye Chaplino, and from a map for Lavrentiya and are thought to be accurate to within a few meters. 


\section{DATA REDUCTION}

REFTEKs digitally recorded seismic data using 1 Gbyte hard-disks in compressed format. After retrieving the REFTEKs from the field, the digital seismic data was downloaded onto DAT tapes in "refdump" format using a Sun workstation (see Appendix 2). The seismic data were then converted to SEG-Y format using a PASSCAL program called "ref2segy". Finally, we converted these SEG-Y data into SEG-Y-formated, common receiver gathers using the PASSCAL program "segygather" (see Appendix 2). Data from the PDAS's were converted from PDAS format to AH format and sent to the PASSCAL Instrument Facility, Palo Alto, to be converted to SEGY using a modified version of "ref2segy". Common receiver gathers were processed and plotted using ProMAX (Appendix 3).

\section{SEG-Y Tape Format}

The common receiver gathers generated from the digital REFTEK tapes are stored in a unreduced travel time format. Sixty seconds of data were saved for each trace in the common receiver gather (6001 data samples per trace). The sample interval is $10 \mathrm{msec}$. The number of traces saved for each common receiver gather varies with each station due to the particular signalto-noise characteristics of each site. The common receiver gathers obtained were written in SEG-Y format to Exabyte tape using the "segygather" program. Data from all three geophone components were converted to SEG-Y format. SEG-Y trace header formats described by Barry and others (1975) were modified slightly, as described in Appendix 4. The header is in EBCDIC format, and the data are in IBM floating point format. See Appendix 3 for a description of the ProMAX flows used to process the SEG-Y data.

\section{DESCRIPTION OF THE DATA}

We next describe the wide-angle seismic data for the two major lines acquired during the Chukchi-Bering Sea experiment. Common receiver gathers are shown in Figures 6 to 19 for 
stations which recorded useful data. Data are presented in the order they were recorded, from south to north for Line 1 and north to south for Line 3 . In these figures the data have been bandpass filtered between 6 and $13 \mathrm{~Hz}$, linearly reduced (moved out) to $8 \mathrm{~km} / \mathrm{s}$, deconvolved with a spiking operator, and stacked (mixed) over five adjacent traces (for details of the processing parameters see Appendix 3). Only vertical component data are shown. Negative ranges are shown for air gun shots to the south of the receiver, positive ranges are for air gun shots to the north of the receiver. In general, data quality are slightly lower than we had expected due, at least in part, to the poor weather and high wind conditions experienced for much of the study. The geophone coupling for the receiver at King Island, a rocky outcrop, was poor, and resulted in very poor data which are not shown here.

Eight sites provided useful recordings of the northbound multichannel seismic (MCS) reflection transect (Lines 1 and 2). The best data were recorded at the northernmost three stations; the lowest quality data were obtained by the southernmost three REFTEK stations. Data recorded at Leitnik, on the eastern end of St. Lawrence Island, are low quality, showing only faint crustal arrivals (Pg) for air gun shots north of St. Lawrence Island to ranges of about $100 \mathrm{~km}$ (Figure 6). The strongest arrivals on this record appear to be PmP reflections at ranges between 60 and 160 $\mathrm{km}$. Faint $\mathrm{Pn}$ arrivals indicate that $\mathrm{Pn}$ crosses over $\mathrm{Pg}$ arrivals at a range of about $125 \mathrm{~km}$. Data recorded at Gambell on the western end of St. Lawrence revealed no crustal arrivals (this data is not shown).

Stations at Provideniya and Novoye Chaplino both recorded Line 1 in a highly-oblique geometry. At both stations arrivals could be traced at offsets of more than $250 \mathrm{~km}$ (Figures 7 and $8)$.

Wide-angle data recorded at Tin City were of high quality (Figure 9). Pg arrivals with an apparent velocity close to $6 \mathrm{~km} / \mathrm{s}$ can be traced discontinuously up to $180 \mathrm{~km}$ south of Tin City. Probable mid-crustal reflections can be observed at ranges between 40 and $60 \mathrm{~km}$. Pn arrivals recorded at Tin City could be traced to ranges in excess of $160 \mathrm{~km}$ south of Tin City, and show that $\mathrm{Pn}$ crosses over Pg arrivals between 110 and $120 \mathrm{~km}$. The apparent Pn velocity at Tin City is 
$8.5 \mathrm{~km} / \mathrm{s}$. The recard obtained at Tin City shows a clear PmP arrival which can easily be traced to within $60 \mathrm{~km}$ of the receiver. Data quality for shots north of the station at Tin City, is not as high as those from south of the station, and arrivals can be observed to ranges of about $100 \mathrm{~km}$.

$\mathrm{Pg}$ arrivals recorded at Little Diomede Island can be traced to ranges of about $150 \mathrm{~km}$ north and south of the island (Figure 10), although the data recorded at this site are considerably noiser than those obtained at Tin City. The crossover of Pn occurs at a range of about $125 \mathrm{~km}$. Faint $\mathrm{Pn}$ arrivals are consistent with a slight southerly dip on the Moho. PmP can be observed both north and south of the station.

Recordings made at Point Hope were the highest quality obtained during our study, yielding Pg arrivals that could easily be traced to offsets in excess of $200 \mathrm{~km}$ for air gun shots north of the Cape (Figure 11). Pn arrivals at Point Hope appear to cross over Pg arrivals at a distance of about $200 \mathrm{~km}$, implying a much thicker crust at Point Hope than in the vicinity of Tin City and Little Diomede Island. A prominent mid-crustal reflection can be observed for air gun shots between 60 and $120 \mathrm{~km}$ north of the receiver. Exceptionally strong converted shear-wave arrivals, having apparent velocities between 2 and $3 \mathrm{~km} / \mathrm{s}$, were recorded at this site.

The REFTEK deployed at Cape Lisbourne recorded large amplitude arrivals to ranges as much as $180 \mathrm{~km}$ (Figure 12). Unfortunately, the internal GPS clock failed to lock onto the GPS satellites, so the internal clock was free running. Correlation of lower crustal reflections with the seismic reflection line collected on the Ewing, however, suggests that the drift of the internal clock probably did not exceed $0.5 \mathrm{~s}$ prior to the acquisition of Line 1 . Furthermore, the drift of the internal clock during the acquisition of Line 1 was probably minor, being less than $200 \mathrm{msec}$. Thus the apparent velocities are likely to be accurate. This record is very similar in appearance to those from Point Hope and Point Lay, except that Pn crossover for shots north of Cape Lisborne is close to $120 \mathrm{~km}$. A strong reflection, interpreted as PmP, is observed at ranges between 85 and $145 \mathrm{~km}$. Pg arrivals, having an apparent velocity of $6 \mathrm{~km} / \mathrm{s}$, can be traced to ranges in excess of $100 \mathrm{~km}$. 
The record obtained at Point Lay is more complex than records obtained at other stations (Figure 13). The recorder at Point Lay provided useful data to offsets in excess of $200 \mathrm{~km}$, although the recorder was located more than $60 \mathrm{~km}$ east of the reflection line. $\mathrm{Pg}$ arrivals can be traced to offsets of about $100 \mathrm{~km}$, and PmP or Pn arrivals appear to cross over in the range of 120 $\mathrm{km}$, at least north of the station. Data acquired for the shots south of the station show considerable complexity for ranges in excess of $120 \mathrm{~km}$.

The records made at Point Hope, Cape Lisbourne, and Point Lay provide reversed refraction coverage along that portion of the northern line. The available data unfortunately do not reverse the wide-angle coverage between Tin City and Point Hope.

Useful wide-angie data were acquired for the southward bound MCS Leg (Line 3) at six sites. These include stations at Point Lay, Tin City, Novoye Chaplino, two sites at Provideniya, and Gambell. The station at Point Lay recorded data in a highly-oblique geometry at ranges between 150 and $200 \mathrm{~km}$ from shots along Line 3 (Figure 14). The arrivals appear to be either Pn or PmP arrivals, but they can be traced only over short distances.

High quality data were recorded at Tin City, where Pn arrivals could be traced about 400 $\mathrm{km}$ to the north and and $\mathrm{Pg}$ arrivals could be traced at least $300 \mathrm{~km}$ to the south of the receiver, respectively (not shown in Figure 15). The arrivals recorded at Tin City during this southbound leg are very similar to those recorded on the northbound leg. In most cases, however, the data recorded during the southern leg have a higher signal-to-noise ratio than those recorded during the northern leg.

Data recorded by PDAS's at Novoye Chaplino and Provideniya for Line 3 were also very high quality (Figures 16 and 17). Arrivals could be traced in excess of $250 \mathrm{~km}$, and frequently in excess of $300 \mathrm{~km}$. Both records obtained at these stations show clear Pg arrivals as well as Pip or PmP reflections. Data recorded by the Guralp at Provideniya is of poorer quality than those recorded at the adjacent PDAS (Figure 18). This difference presumably reflects the substantially different frequency response of the two recorders. 
Gambell recorded relatively poor quality data from the southern transect (Figure 19). Pg arrivals can be traced only to ranges less than $70 \mathrm{~km}$ from air gun shots north and south of Gambell. These arrivals include a prominent reflection branch (centered at offsets of about $60 \mathrm{~km}$ ) for shots north of the station.

All the records obtained show pronounced statics along Pg and Pn branches introduced by topography of seismic basement. These undulations can reach amplitudes of several hundred milliseconds. We believe that these statics originate from variations in the thickness of sedimentary basins along the reflection lines.

We show the seismic ray coverage obtained during our experiment in Figure 20. This figure illustrates where useful wide-angle data were obtained, and shows that the best sampled regions lie in the Chukchi Sea between Point Hope and Point Lay and in the vicinity of the Bering Strait, near the Cape Prince of Wales (Tin City and Little Diomedes Island). The crust between St. Lawrence Island (Gambell) and Eastern Siberia was also well sampled. The crust near Lietnik was sampled to a lesser degree by our wide-angle recording.

Apparent latitudinal variations in wide-angle data quality primarily reflect differences in wind speed conditions during the survey. Wind force and wave height conditions were continuously measured on the Ewing during the survey (Figure 21), and there is a clear correlation between the quality of the wide-angle data and the weather conditions. This correlation is most apparent with the data recorded at Lietnik, because the weather was very bad before the ship arrived offshore Lietnik and gradually improved as the ship steamed north past the station. Looking at the receiver gather for Lietnik useful data can only be seen to the north of the station. The weather was as follows (Figure 21): very stormy to improving past Lietnik, worsened again on the north side of Tin City, and was bad north of Diomede. It then improved north of Point Hope, Cape Lisburne and Point Lay. The weather remained calmer (wind force conditions were generally 3-4) as the ship steamed south past Point Lay and Tin City and then worsened again (wind force normally 5-6) as the station at Gambell was passed. The REFTEK installations at all 
three of these latter sites were comparable, strongly suggesting that wind speed variation accounts for the lower quality data obtained by the recorder at Gambell.

\section{ACKNOWLEDGEMENTS}

Tom Burdette (USGS), and Bill Koperwhats (IRIS/PASSCAL) deployed the REFTEKs and performed the field work in western Alaska. Simon Klemperer, Jon Childs, Brian Galloway, Nikita Bogdanov, Helios Gnibidenko, Terri Plake, Tete Tepano, and Marian Cline served as the Science Party on EWING leg EW94-10. Several native corporations, including the Gambell, Inalik, King Island, and Savoonga Native Corporations provided access to their property. The Cities of Gambell and Pt. Hope and the U.S. Air Force Stations at Cape Lisburne, Point Lay, and Tin City, also provided access to property under their jurisdiction. We thank the IRIS/PASSCAL facility (at Stanford) for providing the REFTEKs and field Sun workstation used for this experiment. Evergreen Helicopter and Ryan Air provided excellent air service; Evergreen Helicopter removed our REFTEK station at Little Diomede Island. Bill Robinson (LDEO), supplied the EWING shot times and locations. Marcos Alvarez and Bill Koperwhats (PASSCAL Instrument Center), reduced the data into SEGY record sections and provided Appendix 3. Jon Child (USGS), Ray Sliter (USGS), and Trond Ryberg (GeoForshshungsZentrum, Potsdam), shared their ProMAX experience. Bruce Julian (USGS), helped us calculate source-receiver ranges. Nikki Godfrey (Stanford Univ.), showed us how to put ranges into the headers. Bruce Francis (LDEO), provided Figures 4 and 5. Nikki Godfrey provided useful comments on an earlier draft of this report.

The UAF group would like to acknowledge the help of our Russian colleagues, Pavel Minyuk, Valentin Kovalev and Andrei Savchenko, as well as Ben Kennedy (UAF) who lost a lot of sleep nursing the Lavrentiya station, Kevin Mackey (Michigan State University) Stephen Crumley (UAF) who helped with the Provideniya and Novoye Chaplino stations and Kaz Fujita (UAF and Michigan State University) who kept communication going in Fairbanks. Jaime Toro (Stanford) also helped in numerous ways. Bering Air were very helpful and friendly in getting us over to Provideniya, and perhaps more importantly, getting us back on time. Jim Fowler (PASSCAL), wrote the AH to SEGY filter for the PDAS data. Marcos Alveras (PASSCAL Instrument Center), reduced the PDAS data into SEGY record sections.

The USGS part of this work was supported by the Deep Crustal Studies Program and the Office of the Chief Geologist. Funding for the UAF part came largely from grants from Exxon Corporation, ARCO Alaska, NATO (SA.12-2-02 (ENVIR.LG.930919) 5637(95)LVdC) and the National Science Foundation (DPP-9024088-02). Acknowledgement is made to the donors of The Petroleum Research Fund, administered by the ACS, for partial support for L. Wolf. 


\section{REFERENCES CITED}

Barry, K.M., Cravers, D.A., and Kneale, C.W., 1975, Recommended standards for digital tape formats: Geophysics, v. 40, p. 344-352.

Galloway, B.K., and Shipboard Scientific Party, EW94-10, 1994, R/V Maurice Ewing Cruise ES94-10: Cruise Report 6 August 1994-1 September 1994, Deep seismic investigation of the continental crust, Bering and Chukchi Seas, Alaska, unpublished cruise report, 30 pp., 9 figures.

Galloway, B.K., Klemperer, S.L., Childs, J.R., and Bering-Chukchi Working Group, 1994, New seismic reflection profiles of the continental crust and Moho, Bering and Chukchi seas transect, Alaska, EOS Trans. AGU, Supplement, v. 75, p. 642.

Kirschner, C.E., 1988, Map showing sedimentary basins of onshore and continental shelf areas, Alaska, U.S. Geological Survey Misc. Investigations Series, I-1873.

McGeary, S., Diebold, J.B., Bangs, N.L., Bond, G., and Buhl, P., 1994, Preliminary results of the Pacific to Bering Shelf Deep Seismic Experiment, EOS Trans. AGU, Supplement, v. 75, p. 643.

Nokleberg, W.J., Parfenov, L.M., and Monger, J.W.H., and Baranov, B.V., Byalobzhesky, S.G., Bundtzen, T.K., Feeney, T.D., Fujita, K., Gordey, S.P., Grantz, A., Khanchuk, A.I., Natal'in, B.A., Natapov, L.M., Norton, I.O., Patton, W.W., Jr., Plafker, G., Scholl, D.W., Sokolov, S.D., Sosunov, G.M., Stone, D.B., Tabor, R.W., Tsukanov, N.V., Vallier, T.L. and Wakita, K., 1994, Circum-North Pacific tectono-stratigraphic terrane map: U.S.

Geological Survey Open-File Report 94-714, 221 pages, 2 sheets, scale :5,000,000; 2 sheets, scale 1:10,000,000.

PASSCAL, Users Guide, 1991, A Guide to Planning Experiments Using PASSCAL Instruments, $28 \mathrm{pp}$. 
APPENDIX 1. R/V Ewing Airgun Firing Times and Locations

\begin{tabular}{cll}
\hline UCT & Lat. (N) & Long. (W) \\
Day:HR:MIN:SEC & Deg.Minute & Deg. Minute
\end{tabular}

Line test 25

220:00:00:13.766 220:03:48:53.934

5857.4170

$58 \quad 47.7070$

Line 1a

220:06:20:01.186 220:07:00:04.832 220:08:00:18.263 220:09:00:19.524 220:10:00:03.257 220:11:00:14.790 220:12:00:02.212 220:13:00:18.033 220:14:00:16.803 220:15:00:16.681 220:16:00:13.534 220:17:00:05.195 220:18:00:07.257 220:19:00:01.763 220:20:00:09.059 220:21:00:01.104 220:22:00:09.652 220:23:00:31.610 221:00:00:03.626 221:01:00:11.207 221:02:00:19.370 221:03:00:01.222 221:03:16:49.460

Line 1c

221:05:56:34.279 221:06:00:01.554 221:07:00:17.505 221:08:00:10.735 221:09:00:03.892 221:10:00:16.149 221:11:00:09.355 221:12:00:21.463 221:13:00:14.714 221:14:00:07.745 221:15:00:00.740 221:16:00:12.632 221:17:00:05.701 221:17:35:53.892

Line 1d

221:17:36:56.059 221:18:00:23.472 221:19:00:11.186 221:20:00:20.006 221:21:00:09.628 221:22:00:01.238 221:23:00:02.929 222:00:00:20.261
$58 \quad 47.5825$

$\begin{array}{ll}58 & 50.4688\end{array}$ $\begin{array}{lll}58 & 54.9298\end{array}$ 5859.3619 5903.7191 5908.1805 $\begin{array}{lll}59 & 12.6918\end{array}$ 5917.3369 5921.8599 5926.3319 5930.8312 5935.3194 5939.8281 5944.3819 5948.8408 5953.2905 5957.7273 6002.2120 6006.7511 6011.2909 6015.9263 $\begin{array}{ll}60 & 20.7365\end{array}$ 6022.0099

16932.4891 16931.7986 16930.6585 16929.7341 16928.6058 16927.7057 16926.5110 16925.4878 16924.3466 16923.3703 16922.1159 16921.0497 16920.1189 16919.0067 16918.0339 16916.8929 16915.7528 16914.7467 16913.5386 16912.5509 16911.3047 16910.0356 16909.7851

6020.4038 6020.6750 6025.9081 6031.1853 6036.2750 6041.2278 6046.0489 6051.0391 6056.0721 6101.2188 6106.4034 6111.7745 $61 \quad 17.2770$ 6120.6420

6120.7396 6122.9558 6128.6843 6134.1837 6139.7630 6145.1985 6150.5507 6155.7795

16910.0437 16909.9741 16908.8639 16907.6007 16906.3233 16905.2144 16903.9810 16902.7480 16901.3202 16900.1198 16858.7856 16857.3610 16855.9946 16855.0994

16855.0821 16854.4906 16853.0807 16851.7275 16849.0389 16847.7493 16846.3065
16931.0150

16935.8248 16850.5031
222:01:00:17.451 222:02:00:16.278 222:03:00:00.179 222:04:00:00.131 222:05:00:12.752 222:06:00:18.082 222:07:00:24.029 222:08:00:21.907 222:09:00:01.427 222:10:00:06.319 222:11:00:14.067 222:12:00:00.258 222:13:00:22.499

222:14:00:14.597 222:15:00:16.467 222:16:00:10.566 222:17:00:20.757 222:18:00:13.887 222:19:00:20.640 222:20:00:12.260 222:21:00:05.776 222:22:00:16.182 222:23:00:24.135 223:00:00:09.763 223:01:00:09.230 223:02:00:09.959 223:03:00:09.314 223:04:09:49.363 223:05:00:09.398 223:06:00:09.441 223:07:00:09.482 223:08:08:29.540 223:09:00:09.595 223:10:00:09.637 223:11:00:10.282 223:12:00:09.739 223:13:00:09.780 223:14:00:09.832 223:14:35:49.868

6200.9640 6206.2210 6211.4316 6216.8809 6222.4038 6228.0032 6233.5179 6236.7310 6237.2039 6237.4618 6237.5579 6237.5092 6237.2986 6236.9756 6236.9030 6234.4857 6231.0626 $62 \quad 27.8271$ 6224.7060 $\begin{array}{ll}62 & 21.7218\end{array}$ 6218.6255 $62 \quad 15.3872$ 6212.0066 6208.3657 6204.9975 6201.4322 6157.8703 6153.6594 6150.8209 6147.4351 6143.8931 6140.0306 6142.9695 6148.0220 6152.9847 6157.8188 6202.6707 6207.4768 $\begin{array}{ll}62 & 10.2248\end{array}$

Line le

223:14:49:09.875 223:15:00:28.832 223:16:00:10.712 223:17:00:28.334 223:18:00:29.592 223:19:00:00.703 223:20:00:27.221 223:21:00:02.219 223:22:00:17.812 223:23:00:25.066 224:00:00:01.623 224:01:00:03.329 224:02:00:02.465 224:03:00:18.246 224:04:00:12.625 224:05:00:25.890 224:06:00:09.779 224:07:00:22.949 224:08:00:22.544 224:09:00:21.875 224:10:00:05.174 224:11:00:16.114

6211.1615 6211.9546

16845.0168

16843.6796

16842.3632

16840.6677

16839.2881

16837.8094

16836.3416

16839.8798

16846.3539

16852.8498

16859.1902

16905.8892

16913.4768

16921.9737

16931.4505

16934.6157

16931.6544

16928.7277

16925.4577

16921.7412

16917.5017

16912.8431

16908.1616

16903.8838

16900.1515

16856.7789

16853.6076

16850.3017

16849.9794

16849.0764

16848.3563

16848.1601

16850.2913

16848.7404

16847.4639

16846.4848

16845.2168

16843.7032

16842.8187 
224:12:00:30.465 224:13:00:02.606 224:14:00:13.340 224:15:00:26.347 224:16:00:22.867 224:17:00:13.741 224:18:00:10.100 224:19:00:19.938 224:20:00:13.054 224:21:00:27.504 224:22:00:00.607 224:23:00:17.885 225:00:00:00.968 225:01:00:07.328 225:02:00:11.561 225:03:00:22.022 225:04:00:20.908 225:05:00:21.806 225:06:00:16.272 225:06:49:31.684

Line 1f

225:06:50:03.443 225:07:00:11.086 225:08:00:01.402 225:09:00:12.508 225:10:00:00.514 225:11:00:10.403 225:12:00:20.303 225:13:00:15.823 225:14:00:11.947 225:15:00:14.799 225:16:00:26.289 225:17:00:02.439 225:18:00:11.580 225:19:00:04.957 225:19:44:26.998

Line 1g

225:19:44:38.981 225:20:00:01.056 225:21:00:25.684 225:22:00:05.345 225:23:00:08.276 226:00:00:22.706 226:01:00:10.633 $226: 01: 20: 44.826$

Line $1 \mathrm{~h}$

226:01:20:54.058 226:02:00:03.594 226:03:00:08.468 226:04:00:06.965 226:05:00:09.896 226:06:00:17.858 226:07:00:02.499 226:08:00:06.449 226:09:00:13.939 226:10:00:14.112 226:11:00:17.553 226:12:00:15.430
6353.3647 6357.5147 6401.6827 6406.0032 6410.5542 6415.3313 6420.3082 6425.4061 6430.5029 6435.6824 6440.7583 6445.9029 6450.9257 6456.0360 6501.2553 6506.5664 6511.8162 6516.8511 6522.0422 6526.4702

6526.5177 6527.4183 6532.9454 6539.5244 6546.6673 6553.0527 6558.9848 6604.7966 6610.3676 6616.0320 6621.5686 6627.0689 6632.4672 6638.1939 6642.2436

6642.2613 6643.6378 6648.8252 6653.9502 6659.0440 6703.5082 6707.9490 6709.4709

6709.4825 6712.1154 6713.1759 6713.2145 6713.0444 6712.8142 6712.7181 6712.2680 6709.2387 6705.6871 6701.8469 6658.3781 $\begin{array}{lll}168 & 02.8008\end{array}$ $168 \quad 02.2314$ 16800.5172 16758.6461 16756.9271

16755.6222

16754.1054 16753.5477

16823.6346

16823.2419

16823.0614

22.7728

16822.1963

16821.9681

$\begin{array}{lll}168 & 21.5567\end{array}$

21.2796

16820.7476

16820.5212

16820.4469

16820.1397

16819.5757

16819.1514

16819.6007

16819.6006 16819.4884 16818.4641 18.4819

$168 \quad 17.5765$

16817.0459

$168 \quad 15.3287$

16813.7833

16809.8436

$168 \quad 07.9474$

$168 \quad 06.1284$

16804.1518

16802.8101

16753.5457 16752.0566 16740.1932 16727.9209 16715.6636 16703.4709 16650.8695 16638.6157 16636.8168 16639.8405

16643.4992

16646.2653
16824.3232
226:13:00:03.676

226:14:00:10.917

226:15:00:02.720

226:16:00:18.831

226:17:00:17.731

226:18:00:14.634

226:19:00:12.724

226:20:00:20.026

226:21:00:12.717

226:22:00:11.988

226:23:00:08.909

227:00:00:07.442

227:01:00:03.142

227:02:00:19.512

227:03:00:07.746

227:04:00:04.177

227:05:00:03.547

227:06:00:13.131

227:07:00:18.557

227:08:00:19.499

227:09:00:12.931

227:10:00:16.092

227:11:00:14.596

227:12:00:06.469

227:13:00:16.246

227:14:00:13.098

227:15:00:01.809

227:16:00:03.039

227:17:00:13.333

227:18:00:38.829

227:19:00:06.414

227:20:00:19.903

227:21:00:03.076

227:22:00:19.974

227:23:00:16.320

228:00:00:15.710

228:01:00:03.912

228:02:00:15.641

228:03:00:07.685

228:04:00:12.447

228:05:00:01.609

228:06:00:01.650

228:07:00:19.731

228:08:00:08.852

228:09:00:03.305

228:10:00:14.213

228:11:00:15.245

228:12:00:08.958

228:13:00:20.228

228:14:00:11.172

228:15:03:40.301

228:16:00:08.263

228:17:00:18.532

228:18:01:48.545

228:19:00:11.089

228:20:04:15.682

228:21:00:19.147

228:22:00:16.168

228:23:00:17.976

229:00:00:05.853

229:01:07:12.683

229:01:39:42.797

Line $2 \mathrm{a}$
6654.4430

6650.0590

6649.2623

6649.4385

6649.4605

6649.5478

6650.2228

6651.7594

6656.3416

6701.0138

6705.4226

6709.9774

6714.5990

6719.1342

6723.7647

6728.3867

6732.9782

6737.6533

6742.4036

6747.0603

6751.7503

6756.2766

6800.8502

6805.0956

6809.4004

$68 \quad 13.8409$

$\begin{array}{lll}68 & 18.0817\end{array}$

$\begin{array}{ll}68 & 22.5477\end{array}$

$\begin{array}{ll}68 & 27.1328\end{array}$

6831.5588

6836.0787

6840.4885

6844.7056

6848.8714

6853.0439

6857.4002

6901.4984

6905.4401

6909.1281

6912.9349

6916.7898

6920.7596

6924.3936

6928.2606

6932.0224

6935.8492

6939.6838

6943.5177

6947.3285

6951.0813

6955.0070

6958.5942

7002.0079

7005.2924

7008.3803

7011.8373

7014.8005

7018.0396

7021.2241

7024.4026

7027.9240

7029.6770

16649.5310 
229:02:06:29.019 229:03:00:10.265 229:04:27:51.172 229:04:46:27.863

Line $2 b$

229:04:50:24.790 229:05:00:09.176 229:05:46:14.549

Line 2c

229:05:54:04.903 229:06:00:18.319 229:07:00:03.081 229:08:00:03.891 229:09:00:19.654 229:10:00:19.438 229:1 1:00:16.453 229:12:00:14.368 229:13:00:01.736 229:14:04:25.390 229:15:00:11.820 229:16:00:11.680 229:17:00:18.743 229:18:00:09.985 229:18:07:47.453

Line 2d

229:18:10:58.606 229:19:00:13.494 229:20:00:23.573 229:21:00:22.937 229:22:00:06.420 229:23:00:22.266 230:00:00:08.761 230:01:00:03.520 230:02:00:00.318 230:03:00:05.746 230:04:00:00.089 230:05:00:14.547 230:06:00:18.972 230:06:12:59.665

Line $2 \mathrm{e}$
230:06:13:33.151 230:07:00:02.217 230:08:00:19.439 230:09:00:20.082 230:10:00:08.612 230:11:00:15.915 230:12:00:09.434 230:13:00:13.548 230:14:00:10.419 230:15:00:07.100 230:15:51:30.082

7123.7190 7125.9405 7128.6814 7131.3541 7134.4531 7136.4751 7138.4054 7141.0417 7145.6743 7149.5476 7147.2073

Line 3a
7033.2420 7032.8708 7034.1650 7035.8247 7037.3973 7039.0326 4269 7043.9839 7045.5250 7047.1033 48.7793 7050.4268
7050.6397

7050.7305 7052.5250 55.3386 7101.0044 $\begin{array}{lll}71 & 03.7200\end{array}$ $\begin{array}{lll}71 & 06.3587\end{array}$ 108.9932 7114.4247 $71 \quad 17.4034$ 7122.2678 7123.0516 7123.6895

15706.6012 15653.2221 15634.6972 15615.1960 15555.9543 15536.0666 15515.1228 15456.1195 15442.4355 15427.2656 15417.1128

232:08:52:15.116 $\quad 7123.2144 \quad 16259.6374$
232:09:00:07.517 232:10:00:15.722 232:11:00:19.801 232:12:00:05.748 232:13:00:04.117 232:14:00:18.436 232:15:00:05.108 232:16:00:13.939 232:17:00:05.633 232:18:00:00.965 232:19:00:08.602 232:20:00:04.665 232:21:00:02.619 232:22:00: 12.668 232:23:00:04.569 233:00:00:06.999 233:01:00:13.370 233:02:00:18.237 233:03:00:09.142 233:04:00:00.234 233:04:45:30.128

Line $3 b$

233:04:46:12.271 233:05:00:04.834 233:06:00:18.415 233:07:00:21.746 233:08:00:04.661 233:09:00:07.088 233:10:00:18.312 233:11:00:13.011 233:12:00:18.706 233:13:00:19.042 233:14:00:10.150 233:15:00:07.495 233:16:00:02.408 233:17:00:08.409 233:18:00:15.359 233:19:00:05.830 233:20:00:13.805 233:21:00:09.045 233:22:00:03.496 233:23:00:17.997 234:00:00:02.618 234:01:00:16.636 234:02:00:19.991 234:03:00:08.749 234:04:00:19.361 234:05:00:17.214 234:06:00:08.763 234:07:00:02.917 234:08:00:09.395 234:09:00:04.748 234:10:00:22.234 234:11:00:05.351 234:12:00:11.702 234:13:00:09.002 234:14:00:00.842 234:15:00:18.285 234:16:00:11.393 234:17:00:34.423 234:18:00:05.136 234:19:00:03.959
7122.8530

7120.1622

$71 \quad 17.5874$

$71 \quad 14.9170$

$\begin{array}{ll}71 & 12.2483\end{array}$

$\begin{array}{lll}71 & 09.6822\end{array}$

$\begin{array}{lll}71 & 07.0277\end{array}$

$\begin{array}{lll}71 & 04.4098\end{array}$

$\begin{array}{lll}71 & 01.7718\end{array}$

7059.2115

7056.4570

7053.7220

7051.0188

7048.2735

7045.6773

7043.0749

7040.3744

7037.8246

7035.4405

7032.9098

7030.9559

7030.9238

7030.3829

7028.1269

7025.6802

7023.2649

7020.6091

$70 \quad 18.0625$

$70 \quad 15.4910$

7013.0782

7010.4589

7007.8560

7005.3213

7002.6854

6959.8163

6955.4329

6951.1240

6946.7288

6942.2238

6937.7868

6933.2865

6928.9179

6924.6373

6920.0805

6915.6726

6911.2370

6906.8463

6902.4604

6858.0692

6853.5963

6849.1857

6844.8462

6840.7364

6836.3657

6831.9318

6827.5155

6822.9826

6818.5813

6814.2658

6810.0441

$\begin{array}{ll}68 & 05.8083\end{array}$
16301.1572

16312.9918

16324.5778

16335.6979

16347.0312

16358.6137

16409.3064

16420.6877

16432.0047

16443.4299

16454.9343

16506.6961

16518.1570

16529.4346

16540.6854

16551.9092

16603.2407

16613.4383

16623.8425

16634.6277

16642.1906

16642.3021

16644.5719

16654.3868

16704.2617

16714.6804

16725.2406

16736.3024

16746.9839

16757.0563

16806.9464

16817.7218

16828.5261

16839.2889

16849.2558

16850.1120

16849.9172

16849.8095

16850.3193

16850.0631

16850.1374

16850.0681

16849.7556

16850.3852

16849.7737

16849.8281

16849.8216

16850.0877

16849.7928

16849.7412

16850.1225

16850.1418

16850.1048

16849.9636

16849.8248

16849.9841

16850.2730

16850.3490

16850.0143

16849.8397

16849.9139 
234:20:00:12.750

234:21:00:08.802

234:22:00:20.079

234:23:00:05.045

235:00:00:18.306

235:01:00:00.646

235:02:00:07.946

235:03:00:12.869

235:04:00:05.411

235:05:00:13.362

235:06:00:10.342

235:07:00:13.992

235:08:00:03.522

235:09:00:08.794

235:10:00:13.630

235:11:00:18.095

235:12:00:03.049

235:13:00:13.257

235:14:00:06.589

235:15:00:17.721

235:16:00:10.783

235:17:00:22.363

235:18:00:18.764

235:19:00:09.603

235:20:00:09.444

235:21:00:16.699

235:22:00:01.340

235:23:00:04.721

236:00:00:01.933

236:01:00:00.193

236:02:00:18.754

236:03:00:19.166

236:04:00:10.907

236:05:00:15.019

236:06:00:16.577

236:06:01:01.869

Line $3 c$

236:06:01:37.237

236:07:00:13.479

236:08:00:10.089

236:08:33:48.244

Line 3d

236:08:34:40.904 236:09:00:22.822 236:10:00:08.604 236:11:00:11.114 236:12:00:13.646 236:13:00:11.757 236:14:00:15.652 236:15:00:13.722 236:16:00:16.260 236:17:00:12.931 236:18:00:08.566 236:19:00:03.836 236:20:00:02.031 236:21:00:15.807 236:22:00:04.196 236:23:00:05.261 237:00:00:18.541 237:01:00:01.416
6801.5021

6757.1902

6752.6977

6748.2814

6743.8234

6739.4223

6734.9017

6730.3785

6725.8513

6721.3545

6716.8021

$\begin{array}{lll}67 & 12.2737\end{array}$

6707.8526

6703.4746

6659.3075

6655.0972

6650.7379

6646.1651

6641.7767

6637.2586

6632.7842

6628.4321

6623.9598

$66 \quad 19.8517$

$66 \quad 15.8054$

6611.4436

6607.0658

6602.8250

6558.5910

6554.1033

6549.6399

6545.2004

6540.8488

6536.6133

6532.4242

6532.3711

6532.3286 6532.9043 6537.4912 6536.9222

6536.8564 6535.2694 6531.4980 6527.7129 6524.1987 6520.8530 6517.4559 $65 \quad 14.0924$ $\begin{array}{lll}65 & 10.6204\end{array}$ 6507.2862 6503.8957 6500.4417 6457.0533 6453.6281 6450.1916 6446.8421 6443.4566 6440.0622
16850.1736 16854.7633

16852.6093

16848.4346

16849.9154

16849.9526

16850.0324

16849.9570

16849.8928

16850.1947

16849.8689

16849.9324

16849.8223

16849.9240

16849.9464

16849.8946

16850.0117

16850.1279

16850.1241

16850.0788

16850.0763

16850.0478

16849.9383

16850.1316

16849.8447

16849.8774

16850.1027

16850.1088

16850.0194

16850.0238

16850.0282

16850.1230

16850.0836

16849.8605

16850.0209

16850.0620

16850.2592

16849.8656

16850.1831

16850.1773

16848.4057 16850.3106 16855.6088 16900.9162 16907.5773 16914.3581 16921.1220 16927.6577

16934.6382 16940.7744 16947.5074 16954.2993 17000.8919 17007.6849 17014.3142 17021.0452

$170 \quad 27.5717$

17034.2177
237:02:00:12.363

237:03:00:02.219

237:04:00:01.669

237:05:00:11.220

237:06:00:11.650

237:07:00:16.750

237:08:00:09.296

237:09:00:08.550

237:10:00:13.102

237:11:00:02.378

237:12:00:18.530

237:13:00:06.694

237:14:00:21.294

237:15:00:15.703

237:16:00:02.017

237:17:00:08.767

237:18:00:00.587

237:19:00:10.110

237:20:00:21.230

237:21:00:16.877

237:22:00:06.722

237:23:00:01.104

238:00:00:07.159

238:01:00:02.859

238:02:00:11.336

238:03:00:09.557

238:04:00:13.610

238:05:00:10.293

238:06:00:09.163

238:07:00:16.102

238:08:00:11.072

238:09:00:09.735

238:10:00:05.077

238:11:00:16.651

238:12:00:11.598

238:13:00:06.459

238:14:00:00.751

238:15:00:01.405

238:16:00:05.723

238:17:00:02.179

238:18:00:01.389

238:19:00:17.697

238:20:00:11.398

238:21:00:04.610

238:22:00:00.101

238:23:00:03.202

239:00:00:06.421

239:01:00:11.884

239:02:00:10.415

239:03:00:03.987

239:04:00:19.005

239:05:00:20.019

239:06:00:14.962

239:07:00:00.563

239:08:00:08.785

239:09:00:03.770

239:10:00:01.590

239:11:00:14.176

239:12:00:14.301

239:13:00:13.272

239:14:00:07.830

239:15:00:19.150

239:16:00:07.243

239:17:00:14.203

6436.6175

6433.1236

6429.6097

6426.1994

6422.7918

6419.4757

6416.0281

6412.8955

6409.7835

6406.5888

6403.3222

6359.9228

6356.5049

6352.7478

6348.6718

6344.7676

6341.0340

6337.3134

6333.4002

6329.5242

6325.8462

6321.9939

6318.1045

6314.1537

6310.2028

6306.2359

$\begin{array}{lll}63 & 02.3898\end{array}$

6258.5770

6254.6955

6250.7730

6246.9351

6243.0703

6239.2065

6235.3602

6231.5185

6227.6792

6223.8400

6220.0085

6216.2042

6212.4780

$\begin{array}{lll}62 & 08.7684\end{array}$

$\begin{array}{ll}62 & 04.9349\end{array}$

6201.1042

6157.3373

6153.5608

6149.8305

6145.9903

6142.0456

6138.1036

6134.2263 
7.39:18:00:02.946 239:19:00:00.581 239:20:00: 18.390 239:21:00:10.970 239:22:00:12.403 239:23:00:07.301 240:00:00:12.238 240:01:00:15.783 240:02:00:15.845 240:03:00:01.592 240:04:00:17.539 240:05:00:05.342 240:06:00:13.634 240:07:00:07.112 240:08:00:08.836 240:09:00:20.476 240:10:00:00.779 240:11:00:20.897 240:12:00:13.511 240:13:00:15.199 240:14:00:04.454 240:15:00:17.164 240:16:00:20.727 240:17:00:21.013 240:18:00:22.377 240:19:00:13.131 240:20:00:12.374 240:21:00:18.163 240:22:00:00.463 240:23:00:06.517 240:23:59:45.445 241:00:00:08.175 241:01:00:06.797 241:02:00:02.712 241:03:00:15.780 241:04:00:03.862 241:05:00:08.543 241:06:00:03.236 241:07:00:20.278 241:08:00: 16.338 241:09:00:10.827 241:10:00:04.940 241:11:00:02.812 241:12:00:12.912 241:13:00:03.596 241:14:00:15.965 241:15:00:11.749 241:16:00:15.742 241:17:00:25.943 241:18:00:14.560 241:19:00:19.171 241:20:00:11.914 241:21:00:02.666 241:22:00:29.854 241:23:00:12.922 242:00:00:10.209 242:01:00:08.981 242:02:00:30.487 242:02:29:26.429

Line $3 f$

242:02:30:53.043 242:03:00:04.352
6036.8713

6032.9236

6028.9437

6025.0967

6021.2027

$60 \quad 17.3948$

6013.6034

6009.8020

$60 \quad 05.8674$

$\begin{array}{lll}60 & 01.9387\end{array}$

5958.0938

5954.1757

5950.3307

5946.4691

5942.6094

5938.8079

5935.0689

5931.2910

5927.3641

5923.5603

5919.6941

5915.8418

5912.1119

5908.1911

5904.5316

5900.6860

5856.9012

5853.0418

5849.2104

5845.2878

5841.4294

5841.4052

5837.4453

5833.5280

5829.7334

5826.0051

5822.2150

$58 \quad 18.2753$

$\begin{array}{lll}58 & 14.5977\end{array}$

5810.9005

5807.2042

5803.4194

5759.5999

5757.4165

5755.7673

5753.9254

5751.9076

5749.9054

5747.8423

5745.7126

5743.5602

5741.5669

5739.3209

5737.4188

5735.8369

5734.1795

5732.3909

5730.6499

5730.4673
17548.5247

17552.8377

17556.9400

17601.2524

17605.4180

17609.4819

$176 \quad 13.5582$

17617.7511

17621.7853

17626.1156

17630.5154

17634.4722

17638.5725

17642.5910

17646.8192

17650.9534

17654.6944

17658.7159

17702.7935

17707.0336

17711.0093

17714.8933

17719.0464

17722.9487

17726.8321

17730.7879

17734.5654

17738.3707

17742.3537

17746.1648

17749.9741

17749.9950

17753.7768

17757.4223

$\begin{array}{lll}178 & 01.2484\end{array}$

$\begin{array}{lll}178 & 04.7171\end{array}$

17808.5961

$178 \quad 12.2596$

$\begin{array}{ll}178 & 15.9798\end{array}$

$178 \quad 19.6589$

$\begin{array}{ll}178 & 23.0790\end{array}$

$178 \quad 26.7943$

$\begin{array}{ll}178 & 29.9499\end{array}$

$\begin{array}{ll}178 & 22.1967\end{array}$

$\begin{array}{ll}178 & 13.6323\end{array}$

$\begin{array}{ll}178 & 05.2801\end{array}$

17757.3071

$177 \quad 49.1219$

$177 \quad 40.9336$

$177 \quad 32.6754$

$177 \quad 24.2885$

$\begin{array}{ll}177 & 15.8495\end{array}$

$\begin{array}{lll}177 & 07.2511\end{array}$

$\begin{array}{ll}176 & 59.3426\end{array}$

$176 \quad 53.3236$

$176 \quad 46.6654$

$\begin{array}{ll}176 & 39.6994\end{array}$

$\begin{array}{ll}176 & 32.6193\end{array}$

$\begin{array}{ll}176 & 29.5107\end{array}$
242:04:00:14.760

242:05:00:08.487

242:06:00:15.446

242:07:00:11.045

242:08:00:18.281

242:09:00:10.877

242:10:00:19.619

242:11:00:08.332

242:12:00:20.713

242:13:00:03.204

242:14:00:07.949

242:15:00:05.536

242:16:00:14.310

242:17:00:15.597

242:18:00:01.561

242:19:00:15.250

242:20:00:06.194

242:21:00:32.885

242:22:00:07.317

242:23:00:33.047

243:00:00:08.108

243:01:00:15.151
5736.2442

5740.1317

5744.0561

5747.8611

5751.6764

5755.4807

5759.3939

5803.2829

5807.2068

5811.1655

$58 \quad 15.2681$

$58 \quad 19.2322$

$\begin{array}{lll}58 & 23.1504\end{array}$

5827.1064

5830.9635

5834.8017

5838.7118

5842.6534

5846.6011

5850.6593

5854.5497

5858.2263 $\begin{array}{ll}176 & 23.6233\end{array}$

$\begin{array}{ll}176 & 19.5473\end{array}$

$\begin{array}{ll}176 & 15.7931\end{array}$

$\begin{array}{ll}176 & 11.7137\end{array}$

$\begin{array}{ll}176 & 07.8046\end{array}$

$\begin{array}{ll}176 & 03.9141\end{array}$

$175 \quad 59.7446$

$175 \quad 55.7562$

$\begin{array}{lll}175 & 51.7376\end{array}$

$175 \quad 47.5156$

$\begin{array}{ll}175 & 43.5441\end{array}$

$175 \quad 39.1712$

$175 \quad 35.0306$

$\begin{array}{ll}175 & 31.0421\end{array}$

$\begin{array}{ll}175 & 27.0073\end{array}$

$175 \quad 23.0172$

$\begin{array}{ll}175 & 18.9931\end{array}$

$175 \quad 14.6570$

$175 \quad 10.4102$

$\begin{array}{ll}175 & 06.1026\end{array}$

$175 \quad 02.0644$

17457.7964 


\title{
APPENDIX 2: CONVERTING REFTEK FORMAT DATA TO RECEIVER GATHERS
}

Below is a step by step description of the processes necessary to convert the continuously recorded REFTEK data into SEG-Y format common receiver gathers. Ths reduction was carried out at the Stanford PASSCAL Instrument facility. To cut 1 day of data with a $100 \mathrm{~Hz}$ sample rate and $20 \mathrm{~s}$ air gun repetition rate requires about 20 minutes of wall clock time. For more detail, please consult the online manual page for segygather.

1. Download compressed data from REFTEK hard drive.

After retrieving the REFTEKs from the field, we downloaded the digital seismic data onto DAT tapes in refdump format using both a Sun workstation and a PASSCAL field DAT drive. The procedure followed for the field DAT drive consisted of the following. A power supply or battery and a hand-held terminal (HHT) were connected to each DAS unit, and SCSI cables were connected from the DAS to the field DAT drive. The field DAT drive was also connected to a power supply. For each station a new DAT tape was inserted into the field DAT drive. Using the HHT the DAT tape was then formated by the following steps: press F5 (Data Menu), press 5 (SCSI Format), press 1 (Format Tape), and press F10 (Start Procedure). With the HHT and power supply still connected to the DAS, and the SCSI cable still connected to the DAT drive, the REFTEK data on the DAS was then written to DAT tape using the following steps: F5 (Data Menu), press 2 (Copy Data), press 8 (Copy Disk to Tape), and press F10 (Start Procedure). Repeating this procedure resulted in 8 DAT tapes, one for each station. We attempted to repeat this procedure twice for each station, one using the field DAT drive and the other using the Sun workstation. For some DAS units, however, it was possible to download the data using the field DAT drive.

If using a Sun workstation, type refdump -d /dev/sd5c /dev/rst1

2. Convert REFTEK formatted data tapes to SEG-Y formatted tapes

use tar $\mathbf{x v f} / \mathbf{d e v} / \mathbf{n r s t 1}$ to read the refdump file from tape and write it to disk

Type:

\author{
mkdir $\mathrm{XXXX}$ (where $\mathrm{XXXX}$ is the station number) \\ cd XXXX \\ $\mathrm{mt}-\mathrm{f} / \mathrm{dev} / \mathrm{rst} \mathrm{Y} /$ rewind \\ ref2seg $-\mathrm{t} / \mathrm{dev} / \mathrm{rst} \mathrm{Y} \quad$ (where $\mathrm{Y}$ is the tape device number)
}

If prompted, enter the sampling rate and gains in $\mathrm{dB}$ for each channel

3. Check REFTEK functioning and obtain station coordinates

These checks were made using the logview program to view the information contained in the REFTEK log file. A plot of the GPS coordinates obtained every hour can be obtained using the GPS tool. The average of these positions is used for the station location. Clock performance can also be assessed via plots of clock phase locking.

First, type logview filename where filename is a REFTEK logfile e.g. 94:231.7300.log. 
Second, click on GPS: Clock window in logview. A plot of all GPS coordinates and statistics on these locations will be provided.

4. Generate shot times file

This file should be in the format:

shot time lat lon

300976 94:222:00:00:48.732 61.9303267 -168.7716050

300977 94:222:00:01:17.243 61.9310033 -168.7714167

300978 94:222:00:01:45.873 61.9316867 -168.7712133

This information is obtained from the shotfile generated on board the EWING (for shotfiles lon is negative in the western hemisphere). A detailed example of how to do this is given below:

1) Combine all shot information into one big file: e.g. big.shot.

2) Edit (vi) timeflt.awk to select needed dates for shottimes.

3) Type awk -f timefilt.awk big.shot >tmp. Puts output into tmp.

4) Type awk -f degmin2degdec.awk tmp >220_228.shotfile where 220_228.shotfile is an example of a shotfile name

5) Type head 220_228.shotfile to look at first few lines of shotfile

6) Type tail 220_228.shotfile to look at last few lines of shotfile

7) vi 220_228.shotfile to delete s.ts.n220: from files vi 220_228.shotfile to change "94-" to "94:" vi 220_228.shotfile to change "94+" to "94:" vi 220_228.shotfile to header line "shot time lat lon" in lower case

e.g. :\%s/94+/894:/g in vi

8) awk ' $\{$ print $\$ 1, \$ 2\}$ ' 220_228.shotfile >220_228.starttime

5. Generate Receiver File (RCVR file)

This file should be in the format:

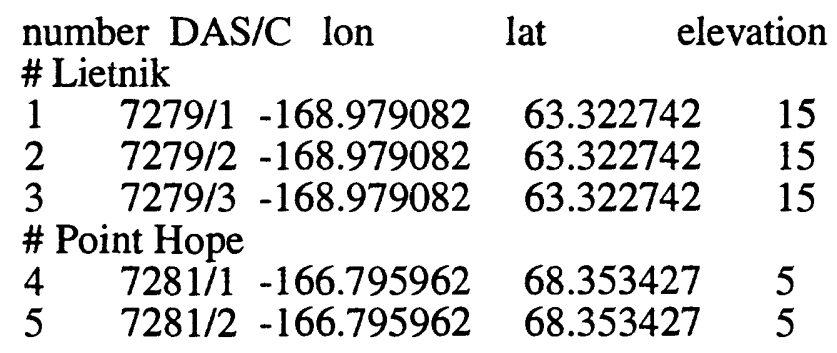


number $=$ arbitrary station number

DAS = REFTEK unit number

$\mathrm{C}=$ Channel ( $1=$ vertical, $2=\mathrm{N}-\mathrm{S}$ Horizontal, $3=\mathrm{E}-\mathrm{W}$ Horizontal)

lon $=$ negative in the western hemisphere

elevation $=$ elevation in meters

Note: The hash sign means the cshell ignores that line

6. Write cshell to produce start times list and cut data.

\section{e.g. segygather.csh}

The same cshell can be used for both operations. First a start times list must be created. This list was created by appending the lists produced for each day in step 2. Secondly the continuous data was cut using segygather. The format is:

segygather $-\mathrm{i}$../starttimes $-\mathrm{s}$../shottimes $-\mathrm{g}$ ../rcvrfile $-\mathrm{d}$ device $-\mathrm{n}$ record_length $-\mathrm{o}$ output_device

An example c-script for Gambell is:

ls /breck/data3/Gambell/R220.01/*.1>/breck/data4/lst/Gambell220_225.1.1st ls /breck/data3/Gambell/R221.01/*.1 >>/breck/data4/1st/Gambell220_225.1.1st ls /breck/data3/Gambell/R222.01/*.1 >>/breck/data4/lst/Gambell220_225.1.1st ls /breck/data3/Gambell/R223.01/*.1 >/breck/data4/1st/Gambell220_225.1.1st 1s /breck/data3/Gambell/R224.01/*.1 >>/breck/data4/1st/Gambell220_225.1.1st ls /breck/data3/Gambell/R225.01/*.1 >>/breck/data4/lst/Gambell220_225.1.1st

segygather -i /breck/data4/lst/Gambell220_225.1.1st -s /breck/data4/shottimes/220_225.shottimes -g/breck/data4/receivers -d 7282/1 -n $60-0 /$ dev/nrst $\$ 1$

The first six lines produce a list of all the start times for days 220 to 225 (the period the EWING was within a reasonable range). The 1 s are for component 1 , the same procedure is necessary for all three components. Segygather is then run using the start times list generated (Gambell220_225.1.1st), the shot file (220_225.shottimes), the receiver file (receivers), the REFTEK unit number and component $(7282 / 1)$. The data was cut to 60 $\mathrm{sec}$, this means that a $60 \mathrm{sec}$ slice of the continuous data was cut for each shot. The shots were separated by 20 to $30 \mathrm{sec}$ resulting in more than one shot being recorded on each trace. The cut traces are then downloaded to tape.

Make one segygather line per line and per channel

When finished editing, type chmod $+x$ segygather.csh to make it executable

Put a new, labeled Exabyte tape in the Exabyte tape drive.

Run program by typing segygather.csh

\section{Load into ProMAX}


The data is now in a format suitable to be loaded into ProMAX. Appendix 2 lists the necessary input parameters. Read tape using ProMAX software and make screen display. to verify segygather worked properly. 


\section{APPENDIX 3. ProMAX 5.1 INPUT AND PROCESSING PARAMETERS}

This appendix contains all the information used to load the Chukchi wide-angle seismic . data into ProMAX 5.1, manipulate the ProMAX database, filter the data, and produce plots. The appendix is divided into three sections. The first describes the structure of the flows used, the second then lists the input parameters for all the ProMAX tools used in the flows. The third describes how we manipulated the database. Substantial revision of these flows may be necessary for ProMAX 6.0.

\subsection{FLOWS}

\subsection{INPUT FROM TAPE TO DISK}

SEG-Y Input

Disk Data Output :

\subsection{PROCESS AND PLOT ADJACENT SHOTS}

This flow was used to realise our first objective, to simply plot the data for a 'first look'. Thus no velocity reduction was applied and all traces were plotted with equal spacing.

Disk Data Input

Trace DC Removal

Bandpass Filter

Automatic Gain Control

Spiking/Predictive Decon

Create CGM+ Plotfile

Plot CGM+ Plotfile ZGS

\subsection{GEOMETRY}

Non-standard geometry is difficult in ProMAX. Rather than do the geometry inside ProMAX the necessary parameters were calculated outside ProMAX and then imported to ProMAX. It was necessary, however, to initialise the geometry first which was achieved as follows.

Geometry Installation*

The * indicates it is a standalone tool which does not need Disk Data Input.

\subsection{PROCESSING AND PLOTTING AS A FUNCTION OF RANGE}

This flow was used once the shot-receiver ranges had been imported into the ProMAX database. On each occasion the flow is run the range information must be read from the database it is not stored permanently as a header value.

Disk Data Input

Trace DC Removal

Bandpass Filter

Database/Header Transfer

Trace Header Math

Trace Header Math

Linear Moveout Correction 


\author{
Automatic Gain Control \\ Spiking/Predictive Deconvolution \\ Trace Mixing \\ Trace Header Math \\ Create CGM+ Plotfile \\ Plot CGM+ Plotfile ZGS
}

The two Trace Header Math tools after the Database/Header Transfer load the range and the absolute range into OFFSET and AOFFSET respectively. This transfer allows the velocity tool to be used on the screen display. To plot trace spacing as a function of range you need to assign the range as CDP. To do this the integer value of the range is loaded into the CDP header prior to plotting. The plot is then created in the CDP spatial domain. The conversion to an integer means it is necessary to calculate the range in meters otherwise all shots within $1 \mathrm{~km}$ would be collapsed together.

\title{
2.0 ProMAX 5.1 TOOL PARAMETERS
}

Below are lists of the critical input parameters for the tools used, note that this is not a complete list.

\subsection{SEG-Y INPUT}

Type of storage

Input multiple files from tape(s)

Multiple file selection

Specify input files list

IBM standard label?

Input data's sample rate

Maximum time to input

Get channel number from trace headers

Input trace format

Is this stacked data?

Maximum traces per ensemble

Primary sort header word

Input primary selection choice

Input secondary selection choice

Enter primary tape drive device path name
Tape

Yes

Select

$1 /$

No

10.0

60000.0

Yes

Get from header

No

25000

SHOT

Input ALL

None

/dev/rmt/1

Notes: When selecting which file to load it is only possible to indicate one file at a time. To view more than one channel, first execute the flow, and then change the $1 /$ to a $2 /$ and execute again. When ProMAX gets to the end of the file it states 'Run out of data'. This phrase simply means 'at the end of the file' so select 'stop'.

\subsection{DISK DATA OUTPUT}

Record length to output

Compress the data

Pre-geometry database initialization

0.0

Yes

No

Note: The 0.0 outputs all the data.

\subsection{DISK DATA INPUT}


Trace read option

Select primary trace header entry

Select secondary trace header entry

Select tertiary trace header entry

Sort order for dataset
Sort

Recording channel number

Field file ID number

None

$1: 705550-711400(1) /$

Notes: In some flows it is necessary to indicate all traces for a process in which case it is useful to have the primary trace header entry something that is the same for all traces. In the case of the Chukchi data, channel number is such a field. The secondary trace header entry is actually the one that picks out the required traces.

\subsection{BANDPASS FILTER}

Type of filter

Type of filter specification

Phase of filter

Domain of filter

Frequency values
Single filter

Ormsby bandpass

Zero

Frequency

4-6,13-18

Note: The phase of the filter can either be zero or minimum.

\subsection{AUTOMATIC GAIN CONTROL}

Application mode

Type of AGC scalar

AGC operator length

Basis for scalar application
Apply

Mean

60000

Centred

Note: AGC was applied before spiking deconvolution.

\subsection{SPIKING/PREDICTIVE DECONVOLUTION}

Type of deconvolution

Decon operator length

Operator 'white noise' level

Get decon gates from database?

Select primary decon gate header word

Select secondary decon gate header word

Specify decon gate parameters

Output traces or filters

Apply bandpass filter after decon

Bandpass filter freq values
Minimum phase spiking

1500

0.1

No

Recording channel number

None

1:0-40000/

Normal decon output

Yes

4-6,13-18

Notes: There are two types of spiking deconvolution, 'Minimum phase spiking' and 'Zero phase', the effect of these is the same as with the bandpass filter. The deconvolution operator length is the maximum length of wavelet that ProMAX looks for and collapses to a spike. Parameters five to seven specify where to look for the repeating wavelet. In this case it looks in all traces (they all have a channel number of 1), between 0 and $40 \mathrm{sec}$. This wide time window was necessary before the data had been linearly reduced.

\subsection{DATABASE/HEADER TRANSFER}

Direction of transfer

Number of parameters
Load to trace header from database 1 
First database parameter

First header entry
SIN GEOMETRY RANGE

range

Notes: This tool loads the RANGE values previously loaded into the database and stores them in the attribute range (the two names do not have to be the same). The attribute range can then be used latter in the flow.

\subsection{TRACE HEADER MATHS}

Select mode

Define trace header equation

Fixed equation mode

aoffset=abs(range)

Notes: This tool simply sets the aoffset attribute to the absolute value of the range for each trace. It is useful to put the calculated range in offset and aoffset as this allows the velocity tool to be used on screen.

\subsection{LINEAR MOVEOUT CORRECTION}

Type of LMO application

Header entry used to specify distance

Select primary header entry

Specify velocity parameters
Forward

aoffset

None

8000:

Notes: The distance used must be positive otherwise the timeshift applied will be in the wrong direction for the negative ranges.

\subsection{TRACE MIXING}

Trace mixing algorithm Trace weights for mixing Number of traces to mix over
Weighted mix

$$
0.6,1.0,1.0,1.0,0.6
$$

5

Notes: This tool replaces the center trace by the sum of this trace with adjacent traces weighted as specified by the user. It does not stack the traces hence the total number of traces is not reduced.

\subsection{SCREEN DISPLAY}

\subsubsection{CONSTANT TRACE SPACING}

Number of traces per screen

Maximum number of ensembles per screen

Do you wish to use variable trace spacing?

Select trace display mode

Primary trace labelling header entry

Mode of primary trace annotation

Increment for primary trace annotation

Secondary trace labelling header entry

Trace scaling mode
500

500

No

WTNA

FFID

Incremental

50

None

Conventional

Notes: An ensemble is the group of traces indicated by a single value of the 'primary trace header entry' specified in 'Disk Data Input'. If FFID is specified as the primary entry then the maximum number of ensembles will have to be the same as the number of traces as there is only one trace per ensemble. The best solution is to specify a big number. 


\subsubsection{VARIABLE TRACE SPACING}

Number of traces per screen

Maximum number of ensembles per screen

Do you wish to use variable trace spacing

Header entry for trace spacing

Secondary trace labelling header entry

Mode of annotation

Increment
0

1

Yes

range

range

Incremental

50

Notes: It is only possible to display the data on the screen with variable trace spacing if all the data is displayed on one screen. The user must then zoom in and out to have a closer look if necessary. The 'traces per screen option' must be either 0 , for automatic mode, or a number greater than twice the total number of traces. Ideally the 'primary trace header entry, specified in the 'Input from Disk' should be something that specifies all traces (channel number for the Chukchi data), in which case we can enter one here. Otherwise the 'maximum numberof ensembles' must be greater than twice the number of traces. If the maximum number of ensembles specified is not 1 the automatic mode for number of traces does not work in which case both numbers must be greater than twice the total number of traces. Twice the number of traces must be specified because ProMAX will only display half the number given. A problem occurs if the number of traces is greater than 499 as the largest number that can be entered in either of these options is 9999.

\subsection{CREATE CGM+ PLOTFILE}

\subsubsection{CONSTANT TRACE SPACING}

Plot file name

Plotting units

Spatial domain of plot

CDP increment

Submenu to view

Components list

Posting method

Select header values to post

Include label

Label text

Components list

Trace space (traces/plot unit)

Time scale (plot units/sec)

Start time

End time

Timing lines

Timing annotation increment

Timing annotation format

Trace plot mode

Section gain

Clip limit

Submenu to view

Title box text cgmplot

$\mathrm{cm}$

Input trace order

1

Traces/Plots/Posts/Graphs

Post $>$ Header $>$ FFID

Value

706600-706800(50)

Yes

FFID 
Submenu to view Processing sequence text Processing sequence options Fully Automatic

Notes: Problems were encountered when the file name was changed from the default. The user must specify the actual numbers to be posted in the 'select header values to post'. The maximum number of traces it is possible to plot was about 80 per $\mathrm{cm}$, to do so it must be a variable area only plot. Specifying '-1' in the 'minimum height of side label' results in no label, specifying the default of 0 generates the label automatically. If a label is generated then specifying a 'fully automatic processing sequence' prevents the user entering a generating tool which causes unnecessary complications.

\subsubsection{VARIABLE TRACE SPACING}

Before the create plot tool the aser must insert a Trace Header Math tool specifying the following:

Select mode Fixed equation mode Define trace header equation cdp=int(range)

The critical parameters in Create CGM+ Plotfile are:

Spatial domain of plot $\quad$ CDP Leftmost CDP 250000

CDP increment

Rightmost CDP 250000

Submenu to view Traces/Plots/Posts/Graphs Components list >PRIMARY TRACE DATA<

Trace space (traces/plot units) $\quad 10000$

Notes: The plot will cover the range specified here however there will only be data if the input traces specified in 'Input From Disk' are in this CDP/range interval. The 'Trace space' is now CDPs per plot unit.

\subsection{LOAding RANGeS INTO The ProMax 5.1 DATABaSe}

Firstly the database must be initialized loading all the header values into the database. This is achieved by running the Geometry Installation tool in geometry initialize mode.

New 'header values' for each trace can then be loaded into the database from columns in an ASCII file. One column must contain a number which tallies with a header value that ProMAX 5.1 can key on, for example TRACENO or SIN. Clearly the chosen header entry must contain a unique value for each trace. The other column contains the new header entry to be imported. It does not matter if the ASCII file contains other columns as well.

It is essential that the ASCII file has a value for the new header entry for every trace in the database and they are in the same order. To ensure this is the case it may be useful to export the current header entries in an ASCII file, the additional column of the new header entry values can then be added ensuring that the above condition is met.

\subsection{EXPORTING CURRENT HEADER ENTRY VALUES FROM THE PrOMAX DATABASE}

Select required line and click on 'Database'. 
Click on 'Database' and 'Get'.

Select the order required ('SIN' for the Alaskan data), and the attribute ('GEOMETRY FFID' in this case). A plot of the order against the attribute will then appear.

'Cancel' the window to uncover the graph.

Click on 'Ascii' from the top line and 'Save'.

Click on 'User-defined file', enter path and file name and click on 'OK'. This box will then appear highlighted in the ProMAX ASCII format file box. Note: Problems were encountered when the specified path was not the users home directory.

Click on the required attributes in the attributes box ('SIN GEOMETRY FFID' in this case).

Edit the description if required and click on 'OK'. A window will now appear to confirm saving the file. 'Exit' the database.

\subsection{IMPORTING NEW HEADER ENTRY VALUES TO THE ProMAX DATABASE}

Prepare ASCII file based on the exported one with the new header entry values in an additional column.

Select the required line and click on 'Database'.

Click on 'ASCII' and then 'Client'.

Click on 'File' and enter the path and name of the ascii file to import, then click 'OK'.

Click on 'Order' and select the header entry you wish to key too. This must be a header entry that has a unique value for each trace and is listed in a column in the imported file.

Click on 'Info Type' and select 'Geometry'.

Move mouse to box adjacent to 'Attribute' and type the name of the new header entry.

Click on 'Rows' and type in the rows containing the header values. This can also be achieved by selecting them in the lower window using MB1.

Select the columns which the key header value is in using MB2 in the lower window.

Select the columns the new header entry values are in using MB3 in the lower window.

Click on 'Display', type in a description of the new header entry, and 'OK'.

A plot of the new header entry against the key header enter will now appear (the window can be removed by clicking on 'Cancel').

Save the new header entry by clicking on 'Database' and then 'Save'. Then click on the 'key against new' line in 'New' window. Another window will then appear to confirm the values have been saved.

'Exit'. 


\section{APPENDIX 4. PASSCAL SEGY TRACE HEADER FORMAT}

Byte \#

$$
\begin{array}{r}
1-4 \\
5-8 \\
9-12 \\
13-16 \\
\text { । }-30 \\
\text { । } \\
69-70 \\
\text { । }
\end{array}
$$$$
115-116
$$$$
117-118
$$$$
119-120
$$$$
121-122
$$$$
\text { I }
$$

$157-158$

$159-160$

$161-162$

$163-164$

$165-166$

$167-168$

I

$174-174$

I

$181-186^{*}$

$187-194 *$

195 - 198*

$199-200 *$

$201-204 *$

205 - 206*

$207-208 *$

$209-210^{*}$

$211-212 *$

$213-214^{*}$

$215-216^{*}$

$217-218^{*}$

$219-220^{*}$

221 - 224*

225 - 226*

$229-232 *$

$233-236 *$

$237-240 *$
Description

Trace sequence number within data stream

Trace sequence number within reel (same as above)

Event number

Channel number

Trace identification code $=1$ for seismic data

Elevation constant $=1$

Number of samples in this trace (note if equal 32767 see bytes 229 - 232)

Sample interval in microsecs for this trace (note if equal 1 see bytes $201-204$ )

Fixed gain flag $=1$

Gain of amplifier

Year data recorded

Day of year

Hour of day (24 hour clock)

Minute of hour

Second of minute

Time basis code: $1=$ local $2=$ GMT $3=$ other

Stake number index

Station Name code ( 5 chars +1 for termination)

Sensor Serial code ( 7 chars +1 for termination)

Channel Name code ( 3 chars +1 for termination)

Extra bytes ( 2 chars)

Sample interval in microsecs as a 32 bit integer

Data format flag: $0=16$ bit integer $1=32$ bit integer

Miliseconds of second for first sample

Trigger time year

Trigger time julian day

Trigger time hour

Trigger time minutes

Trigger time seconds

Trigger time milliseconds

Scale factor (IEEE 32 bit float)

(true amplitude $=($ data value $) *($ scale factor $) /$ gain

Instrument Serial Number

Number of Samples as a 32 bit integer

Max value in counts.

Min value in counts.

* Header values not specified in the standard SEGY format 


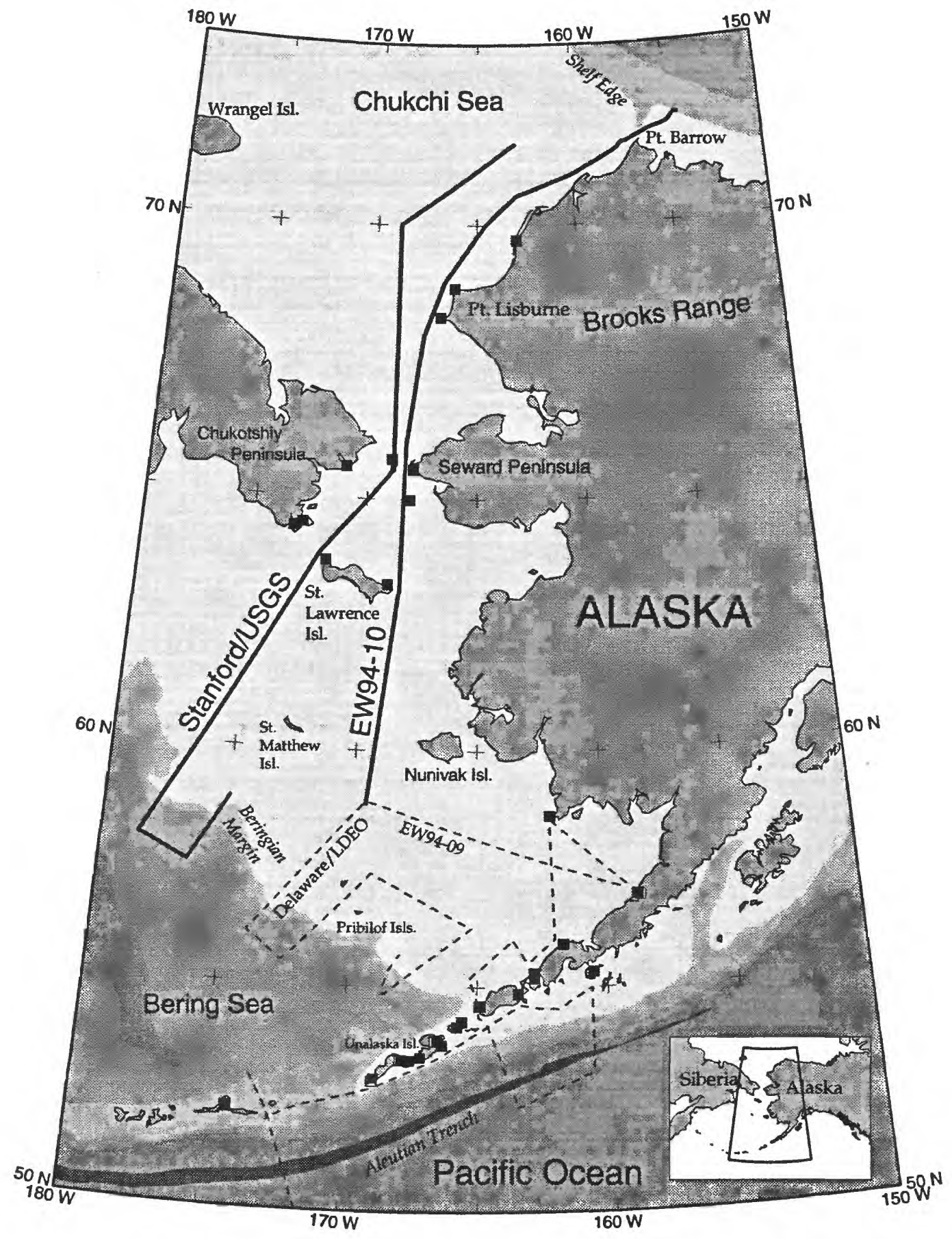

Figure 1. Map showing location of EW94-09 and EW94-10 seismic-reflection surveys in Bering and Chukchi Seas. Filled boxes show locations of Reftek recorders deployed in Alaska and seismic recorders deployed in Russia to record these reflection surveys. 


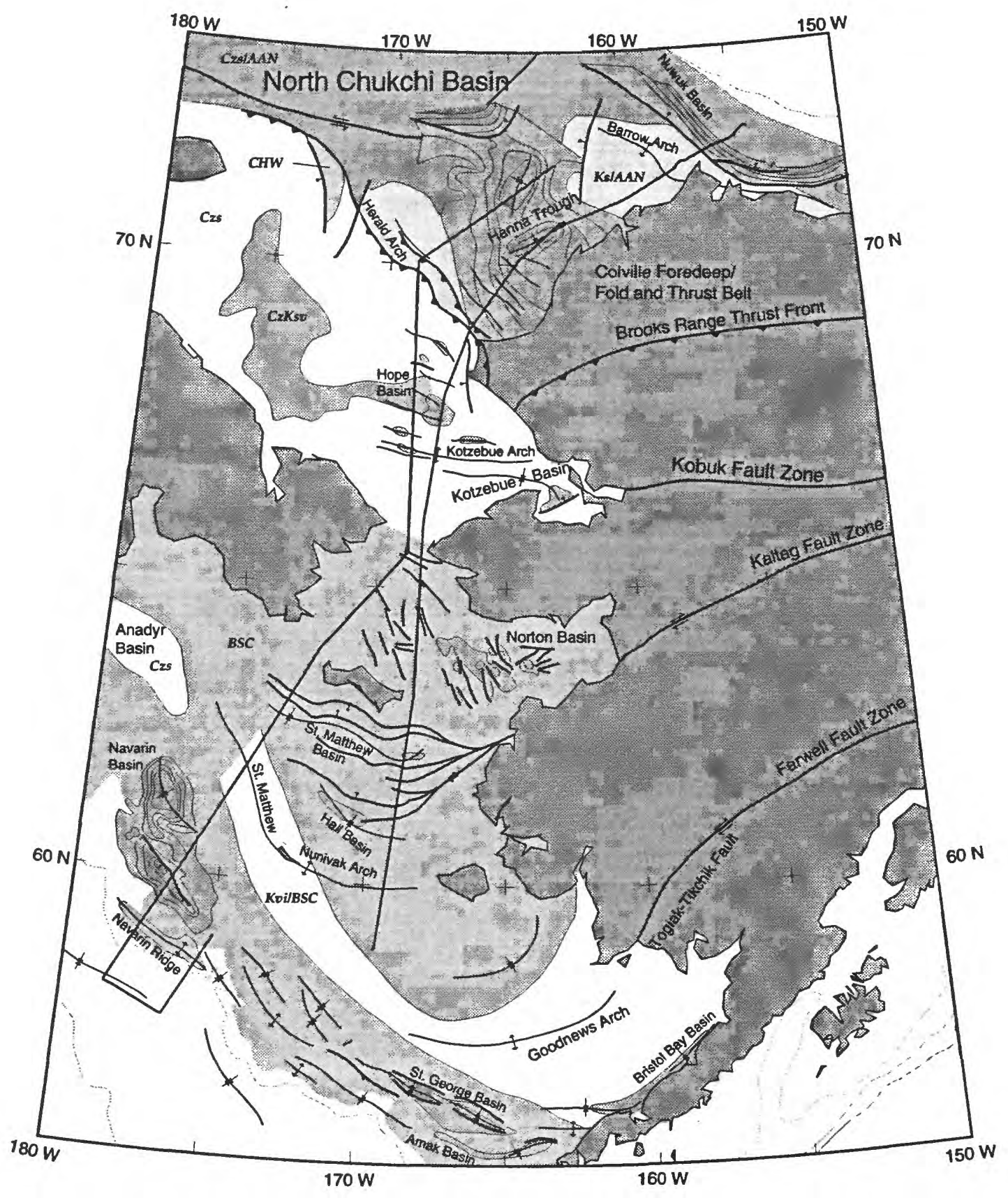

Figure 2a. Geologic map showing main structural trends and elements transversed by seismicreflection lines. 


\section{Legend}

BSC

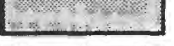

Kvi/BSC
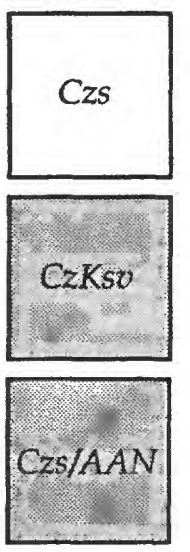

Ks/AAN

CHW

Bering Sea Collage

Bering Sea Collage overlain in parts by Cretaceous volcanic rocks

Cenozoic sedimentary cover overlying North Slope Block

Cretaceous sedimentary cover overlying North Slope Block

Cenozoic sedimentary cover overlying North Slope terrane

Cretaceous sedimentary cover overlying North Slope terrane

Wrangel subterrane

Basin sedimentary thickness are in $2 \mathrm{~km}$ intervals. (Lightest color $-3 \mathrm{~km}$.)

Sources: Kirschner, C. E., 1988; Nokleberg, W. J., and others, 1994.

Figure 2b. Legend for Figure 2a. 


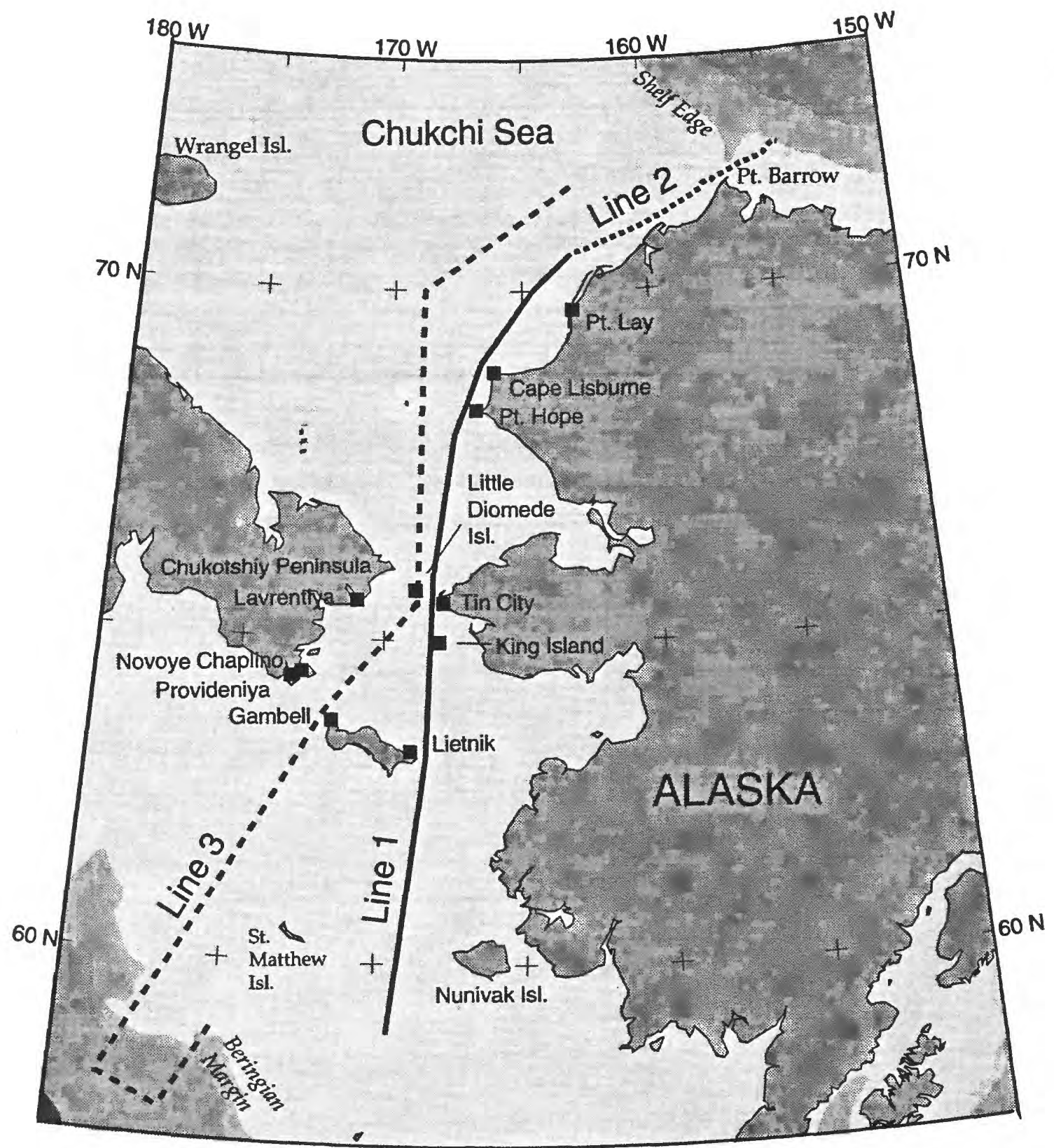

Figure 3. Detail of location map showing Reftek station locations and recorders in Russia. 


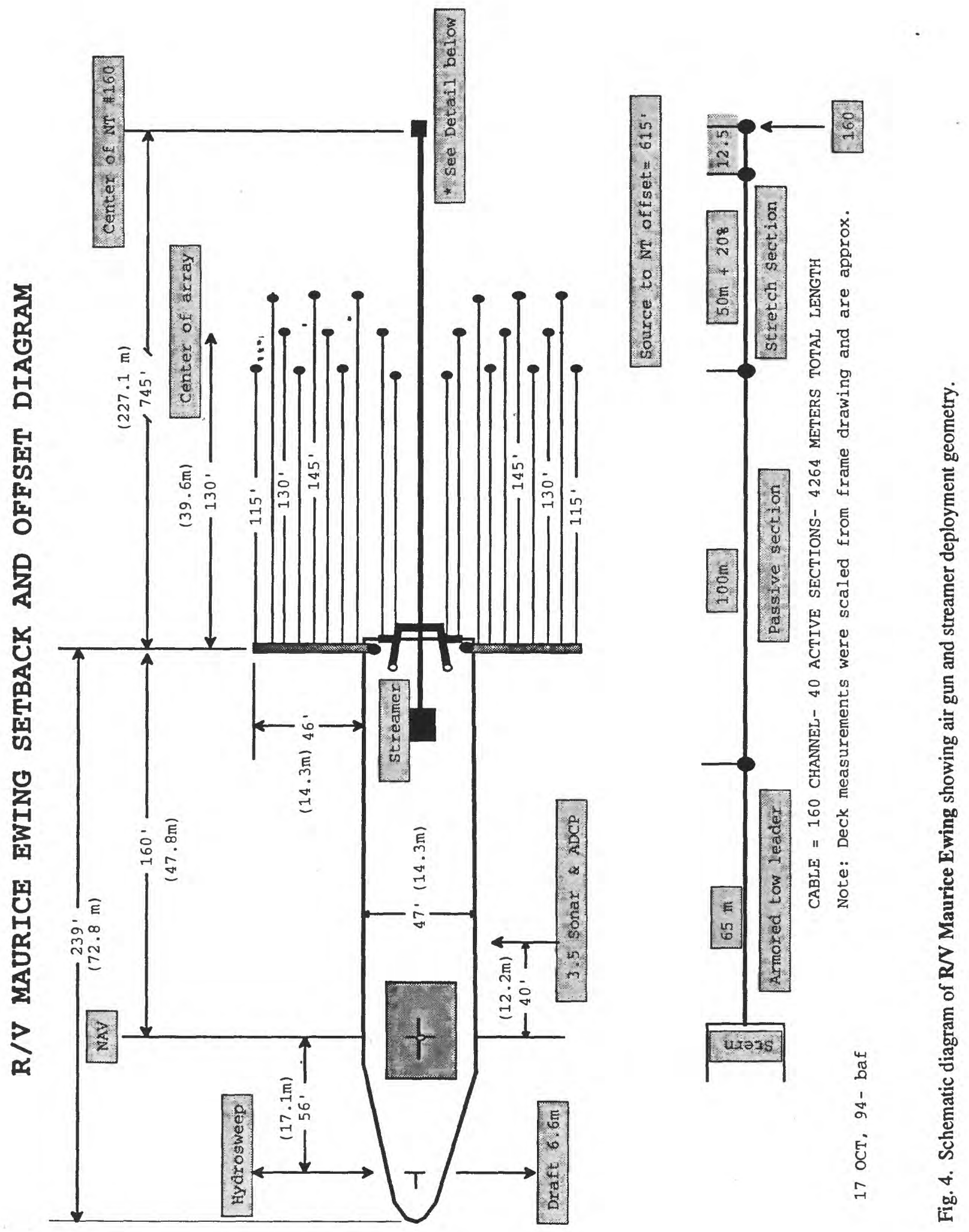




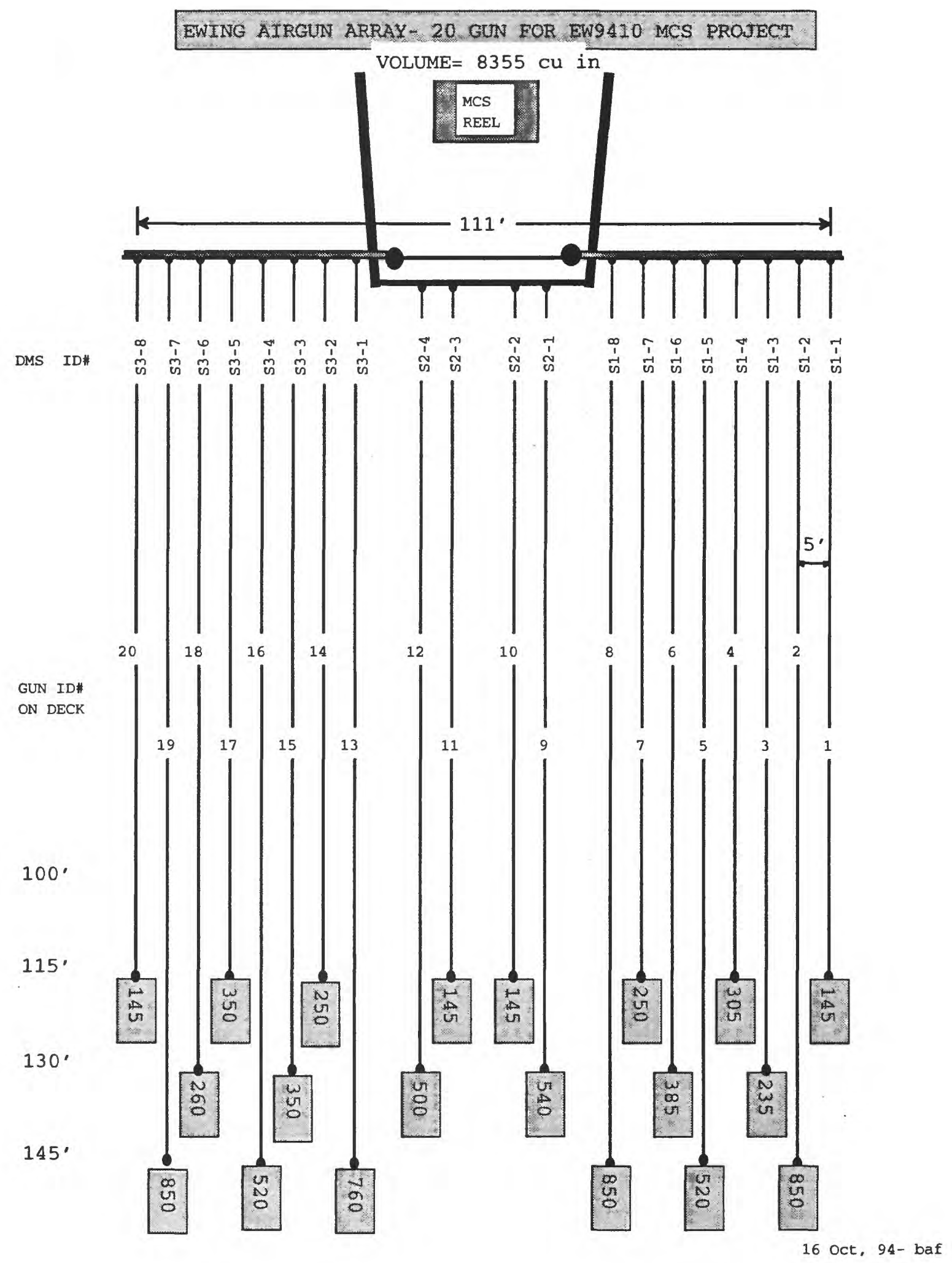

Fig. 5. Detailed schematic diagram of R/V Maurice Ewing air gun array. 

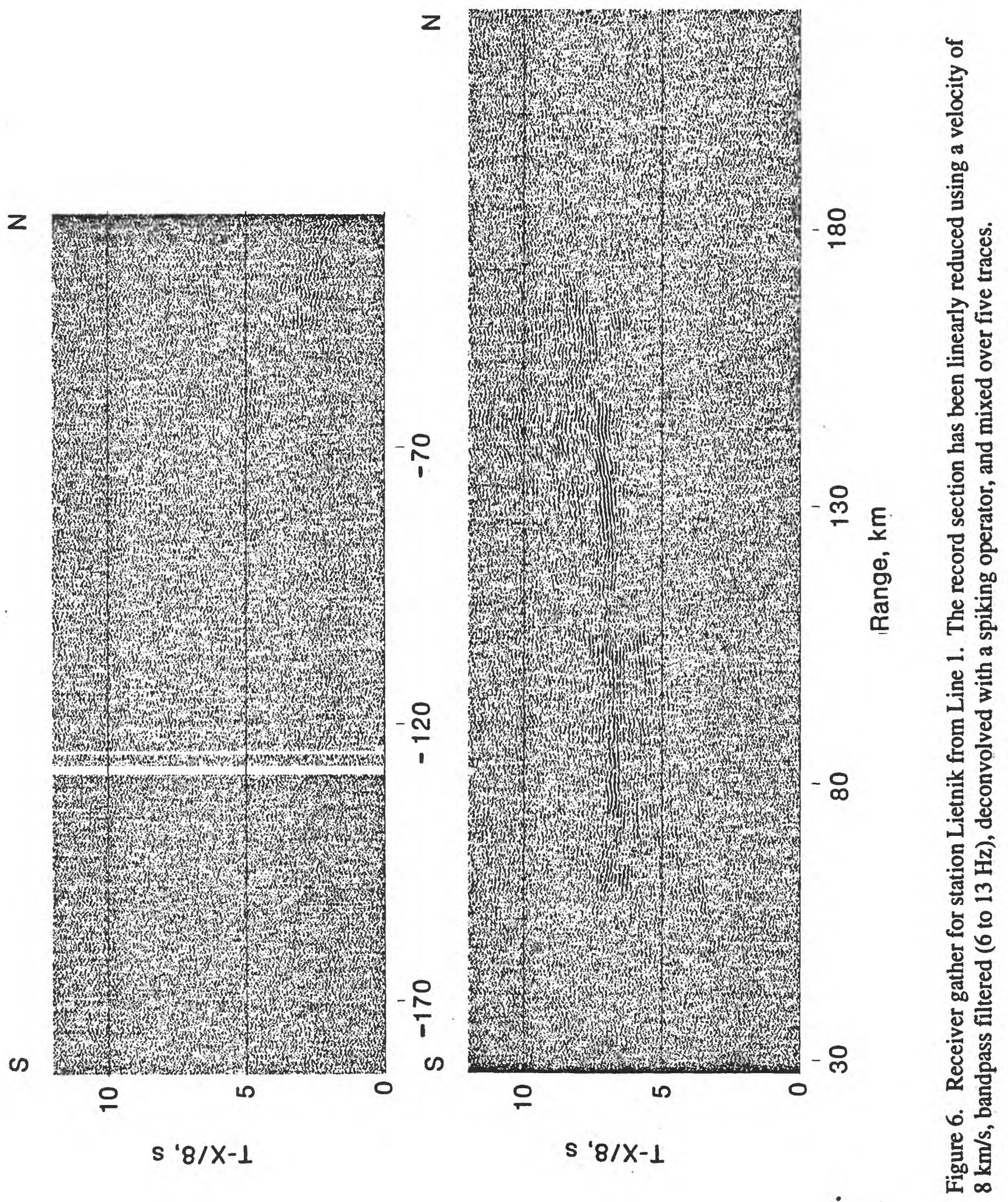

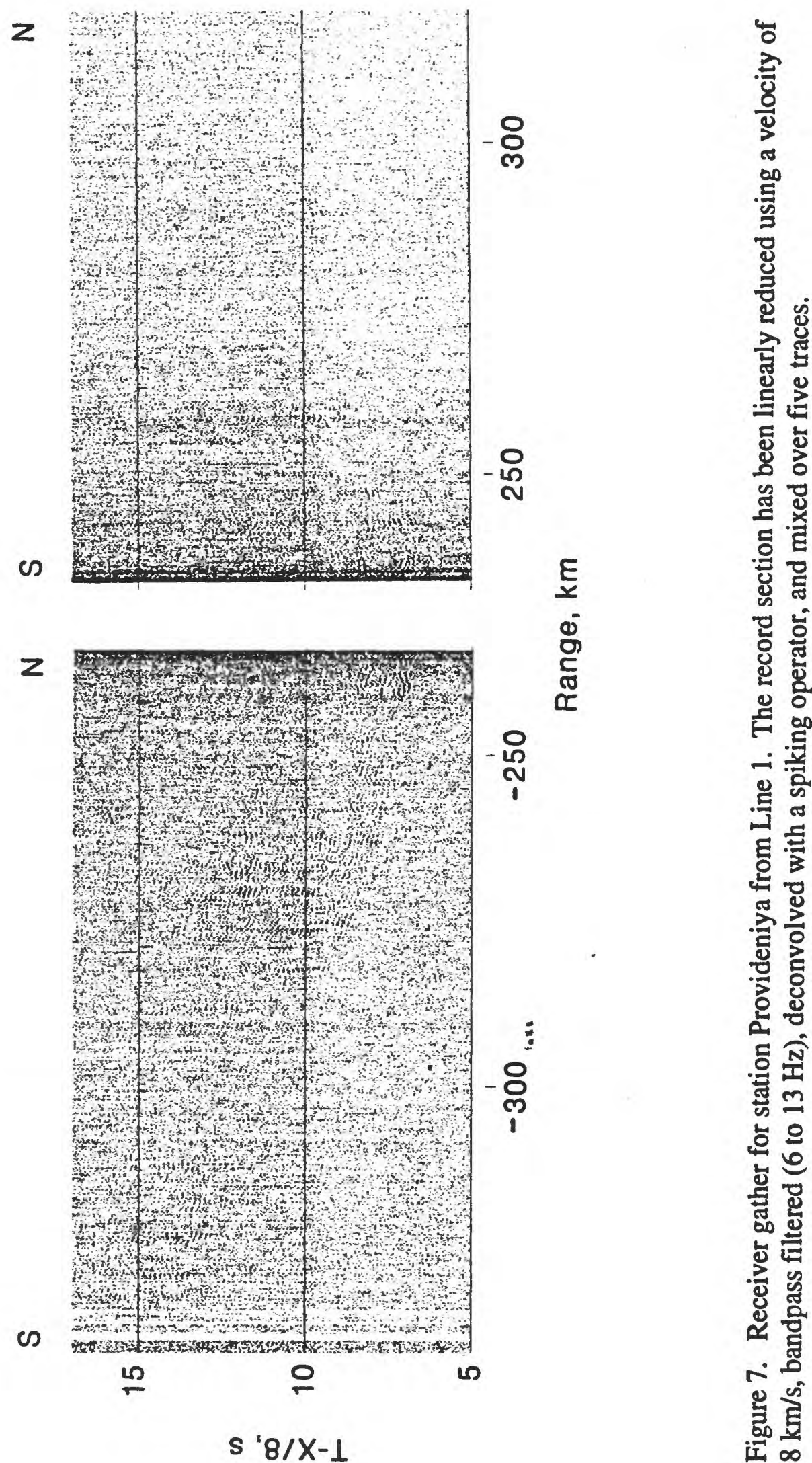

- 유

ญํํ

สี ซ్ల

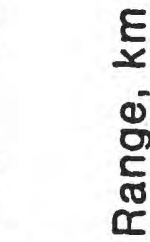

흘

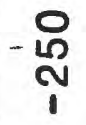

$\frac{0}{0}$

司 듬

융 윯

E

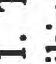

¿

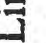

릉 들

은

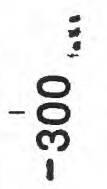

동 존

哥

흥

总

on

흔

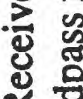

는

․ํ

할 हี 


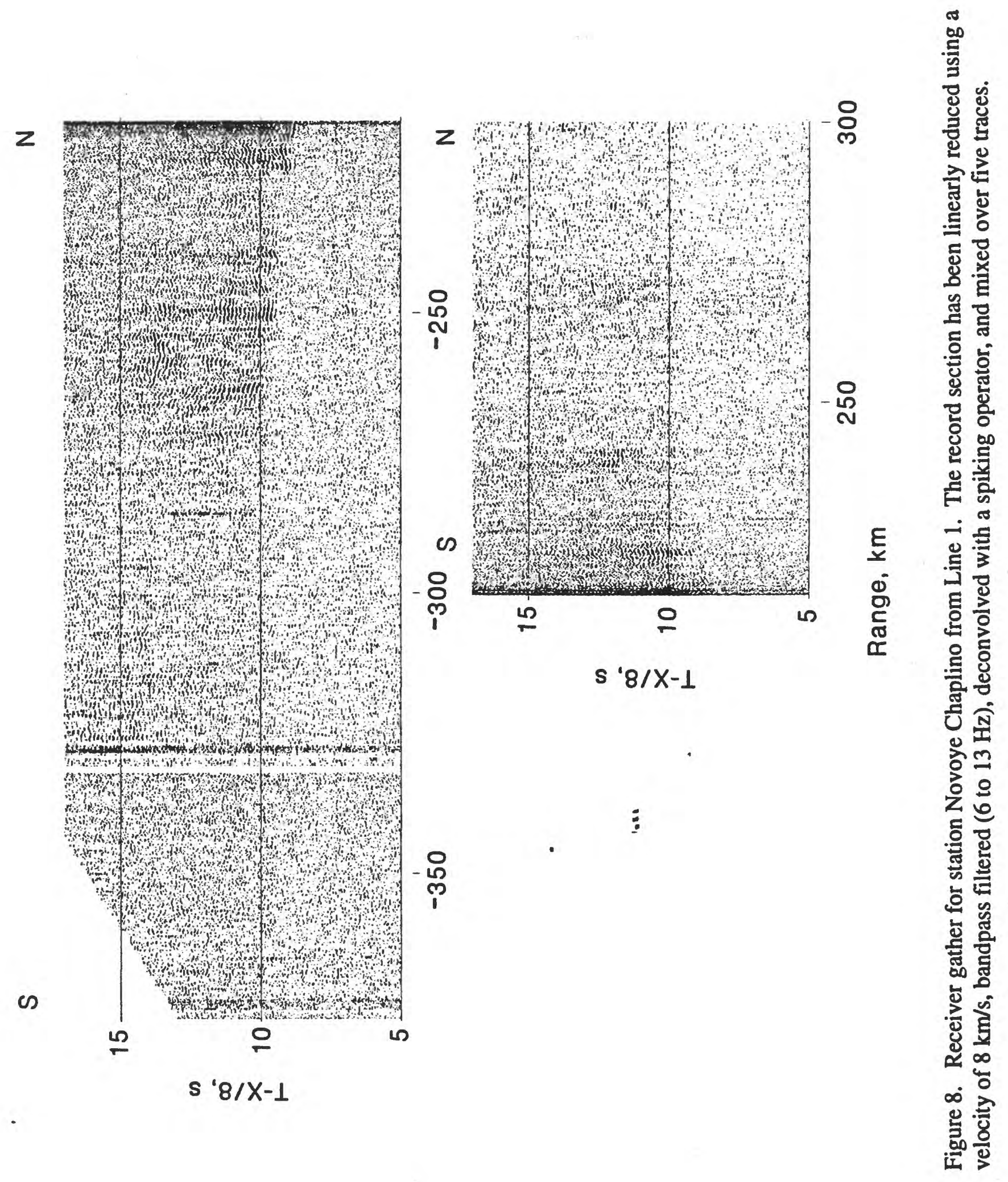



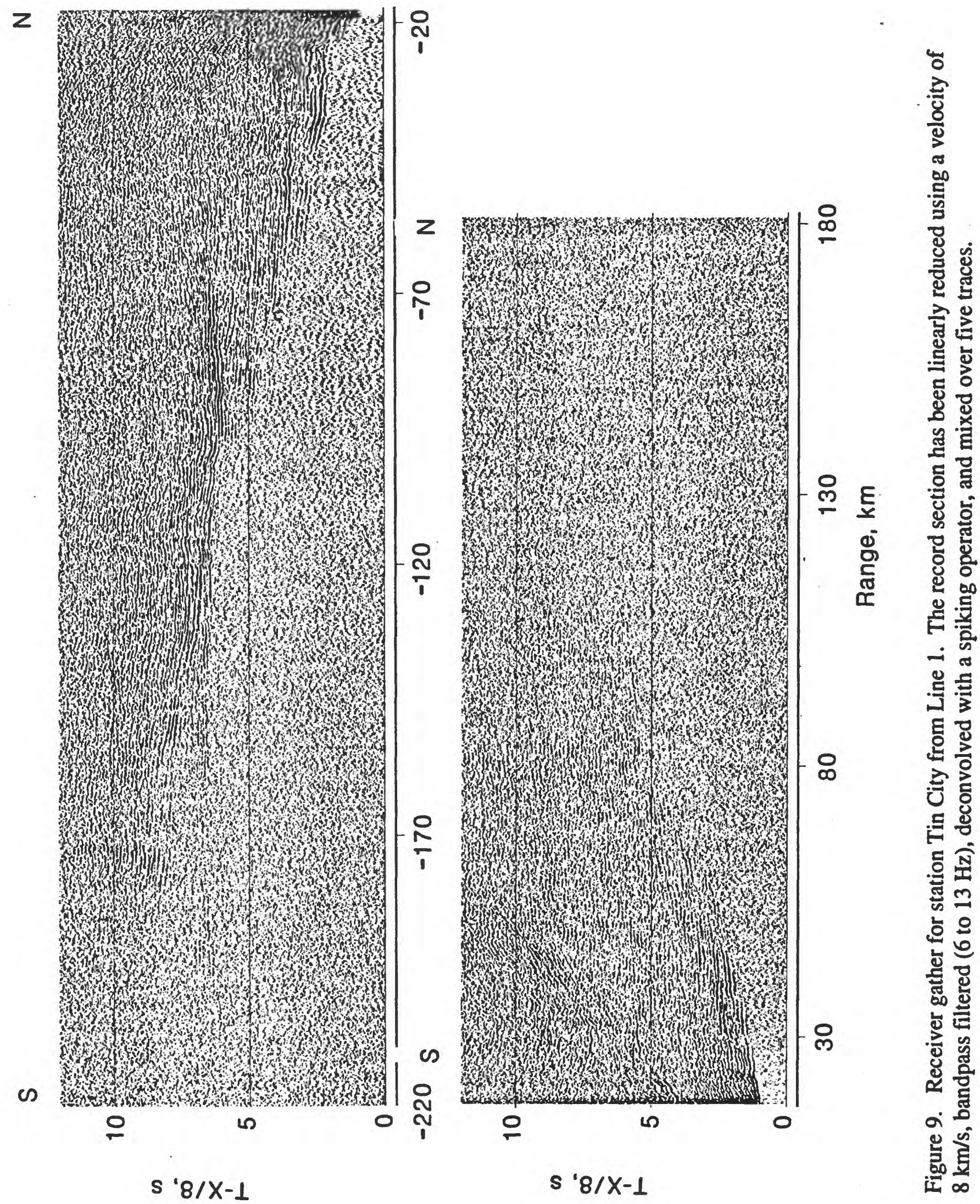

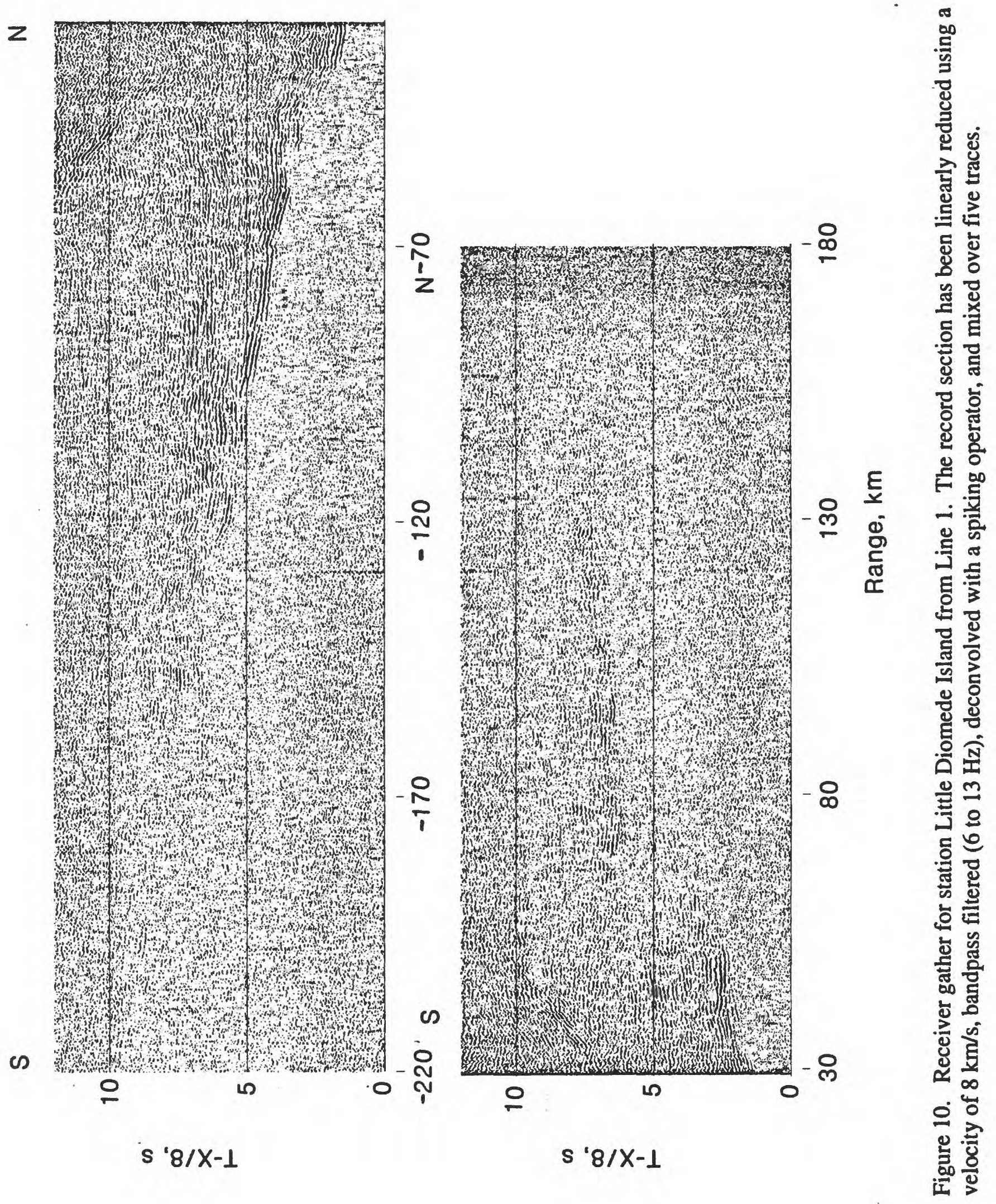


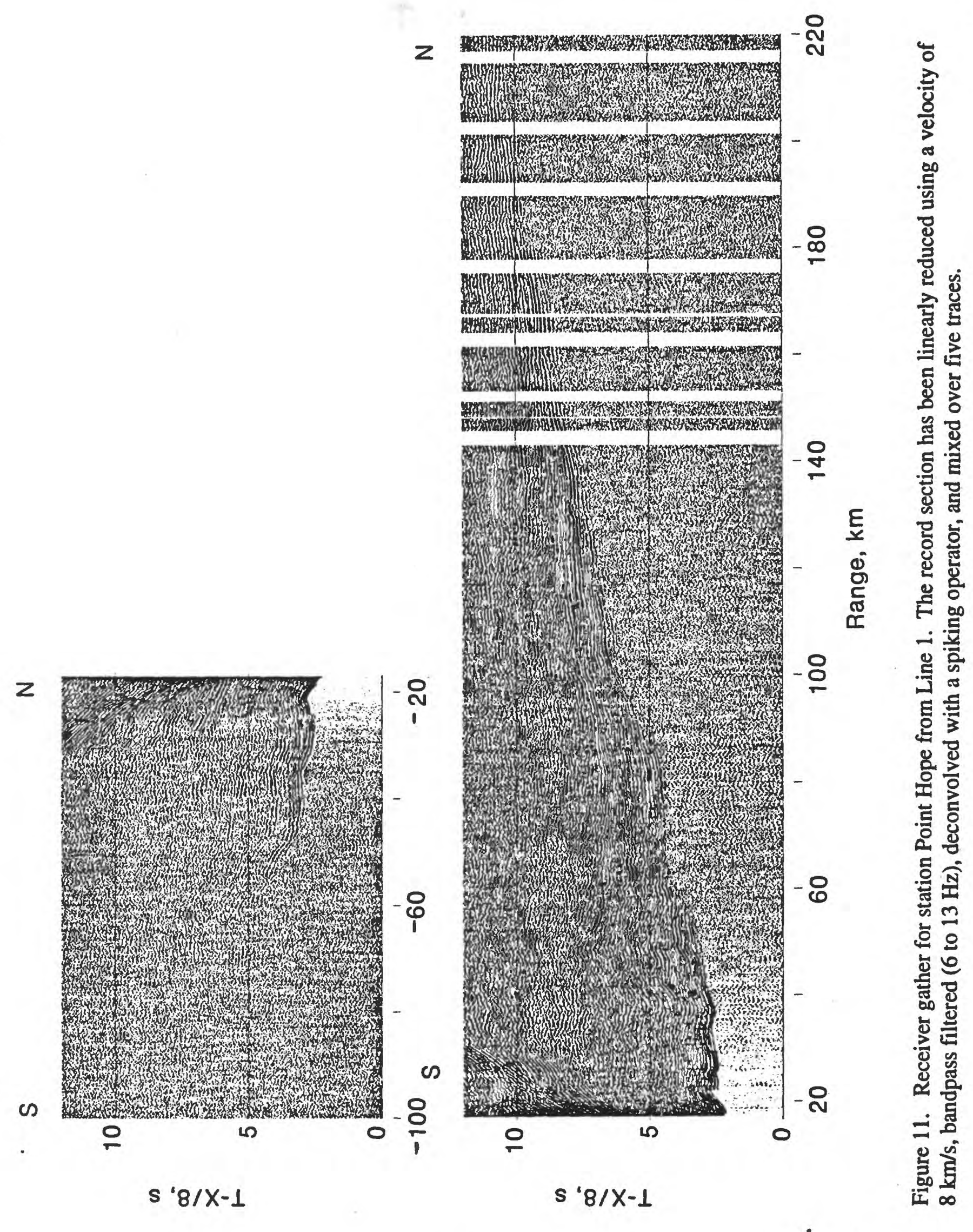




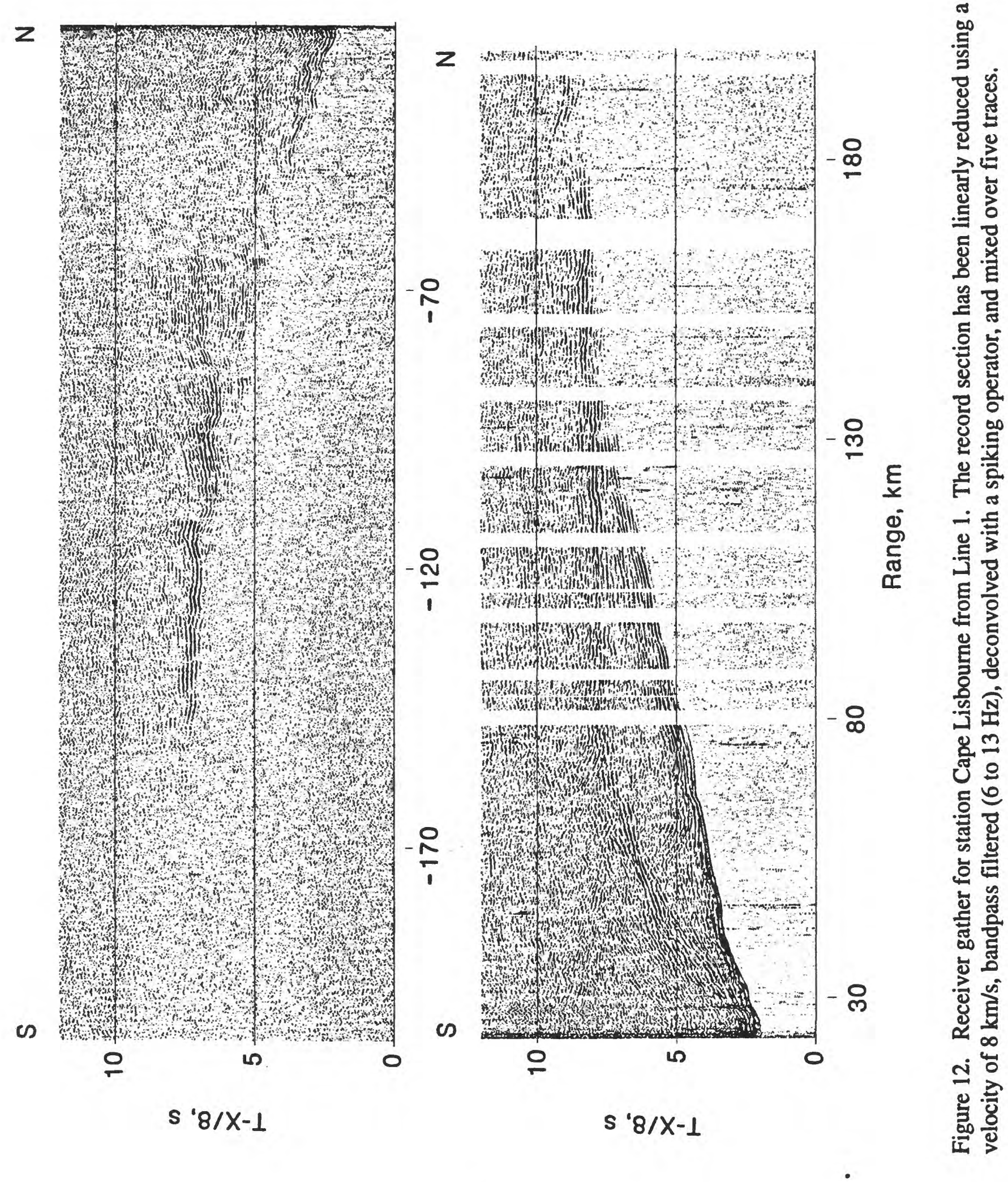




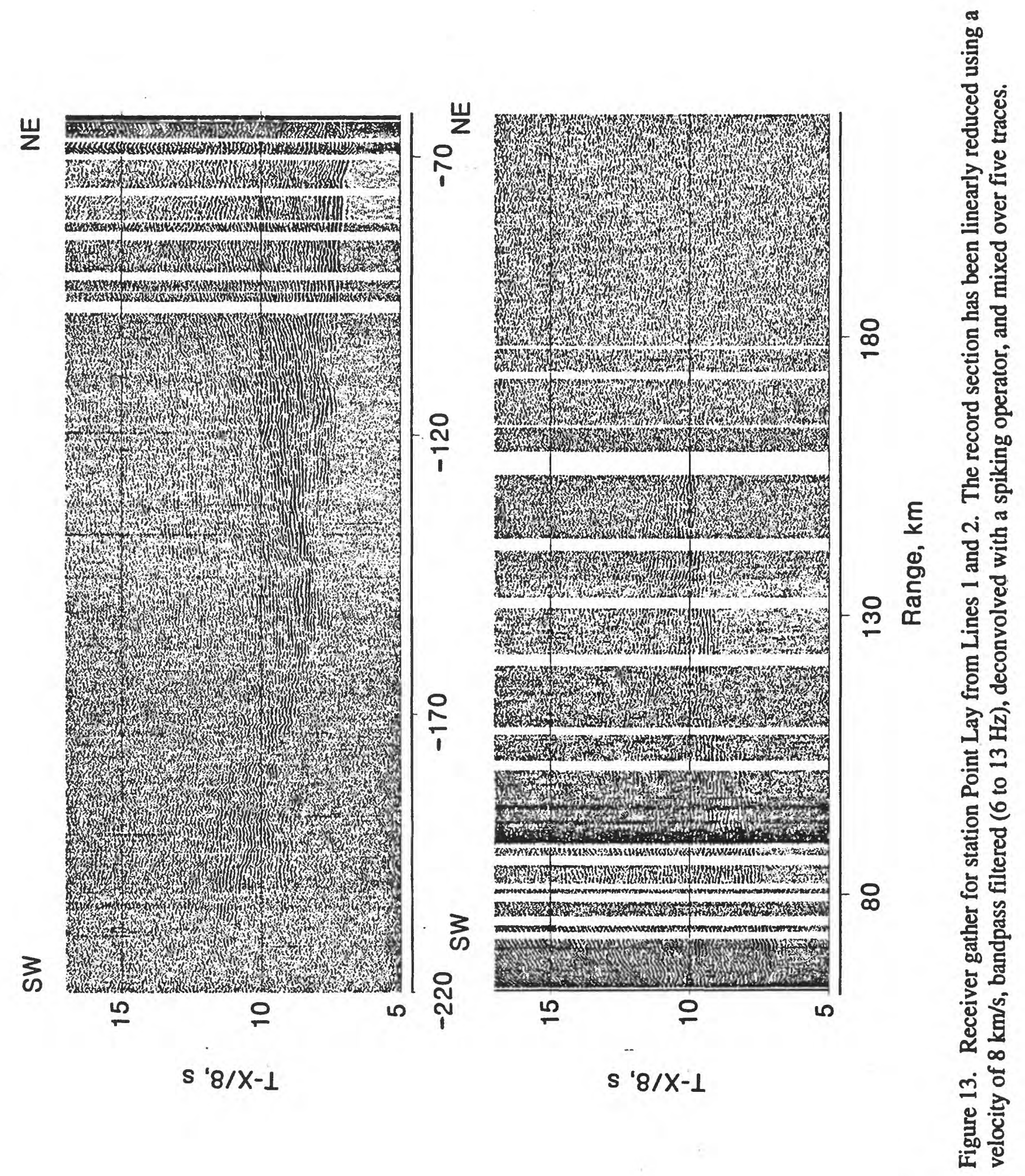




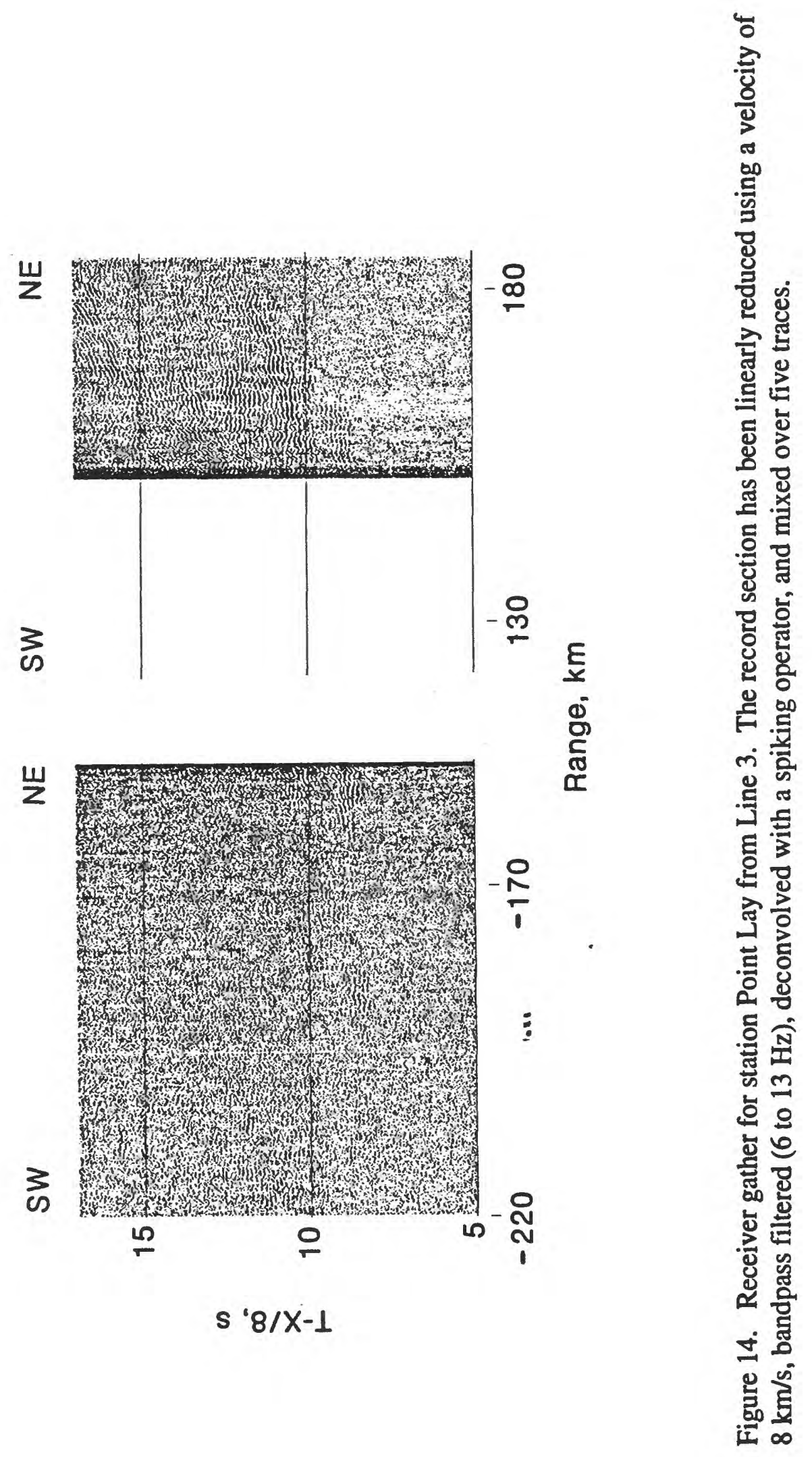




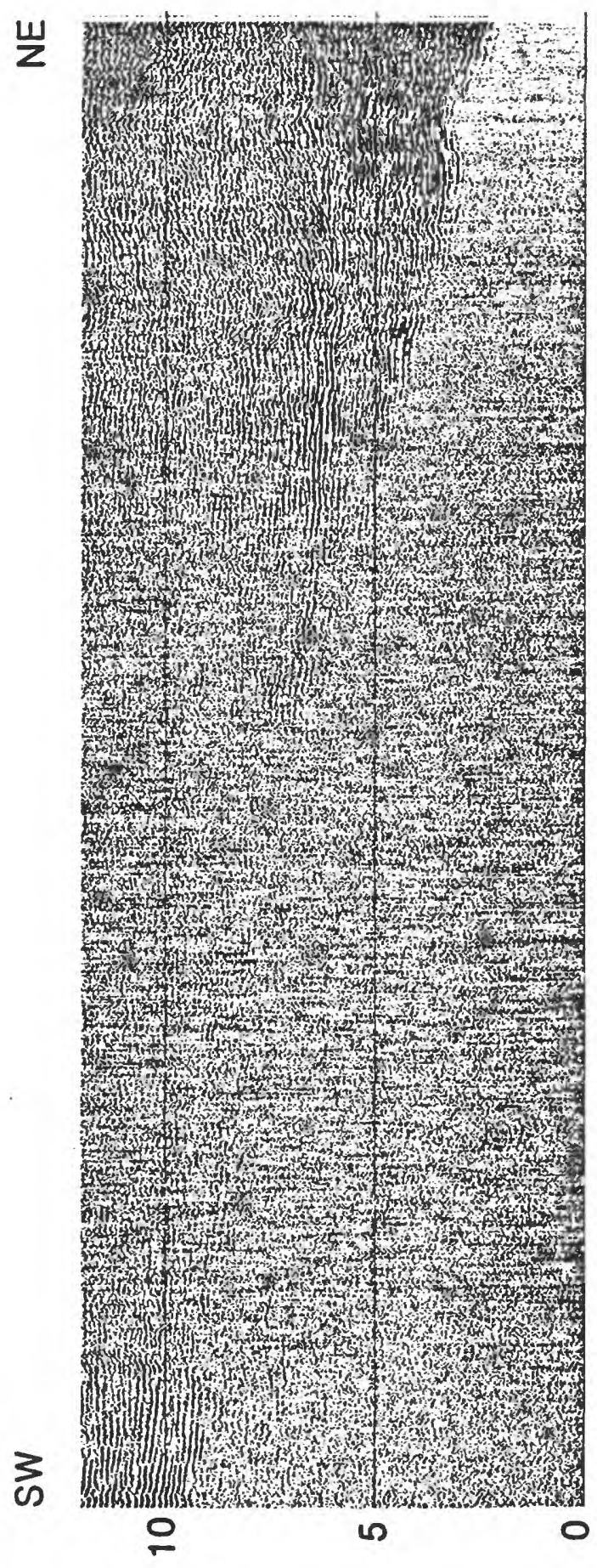

s $8 / X-1$

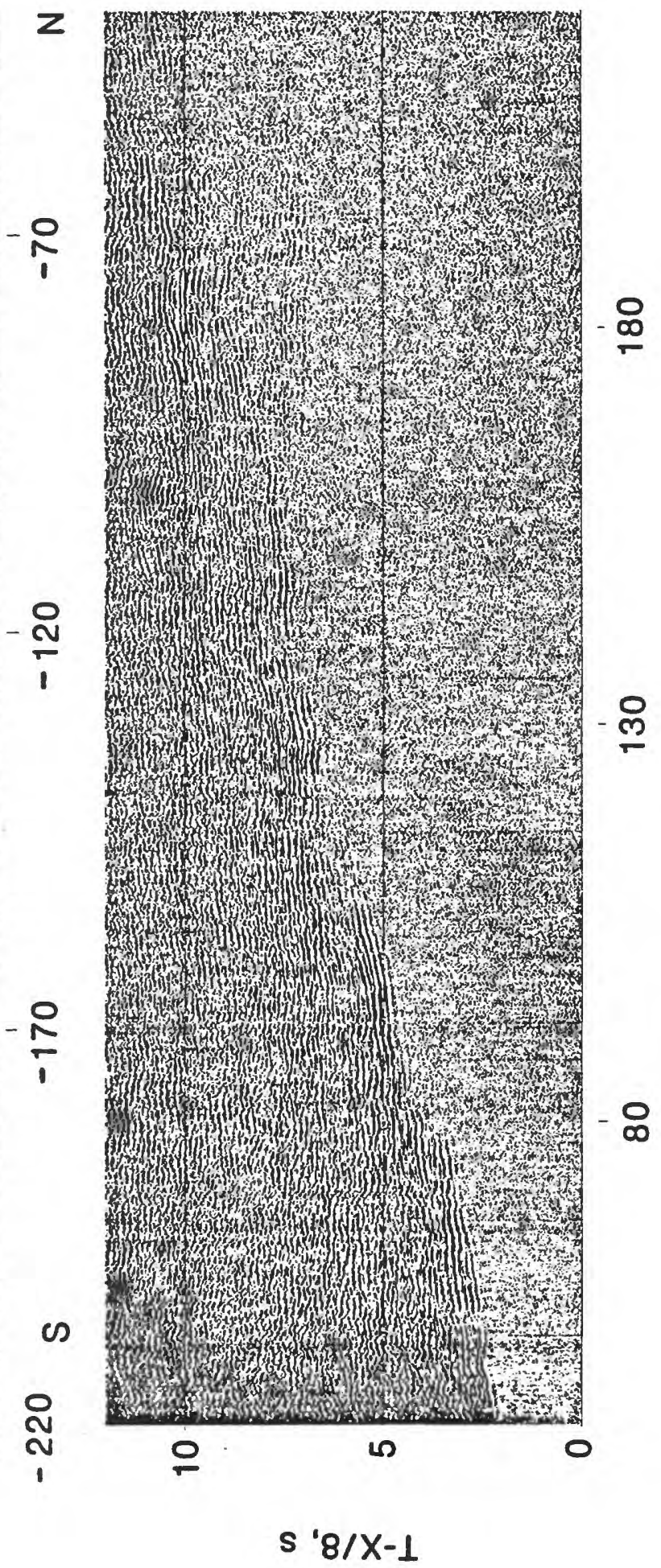

ㅎ

를

.

망

ర్己

출

.

ฐี

8

胥

드 흘

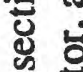

등 갱

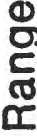




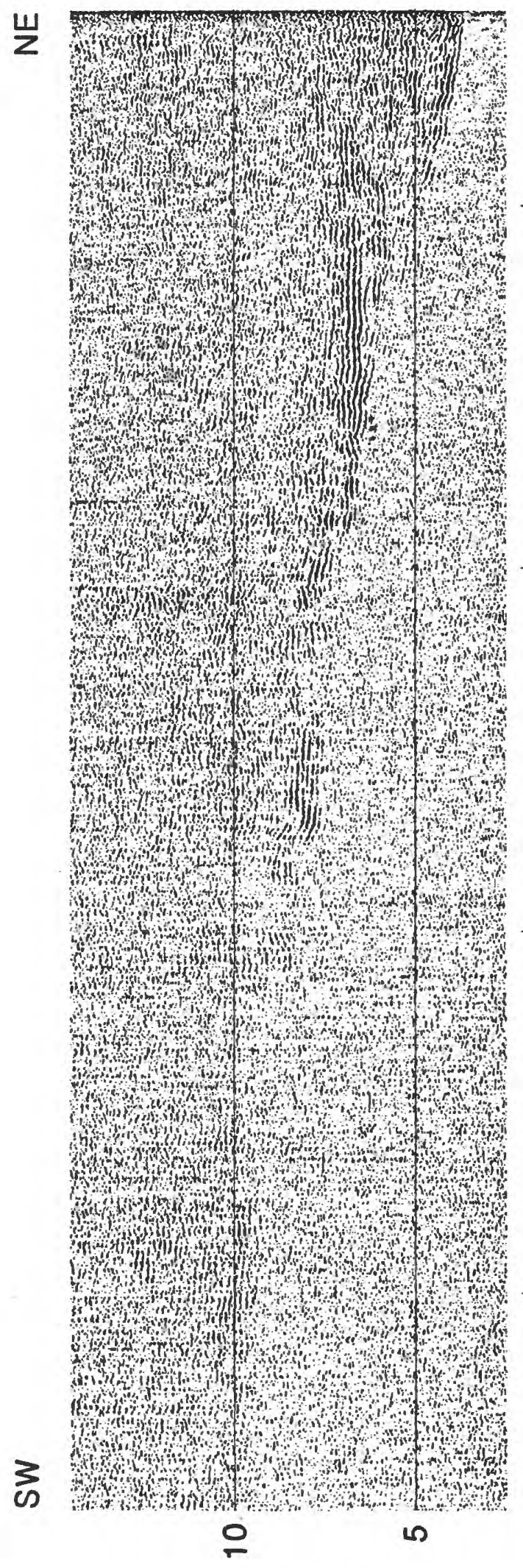

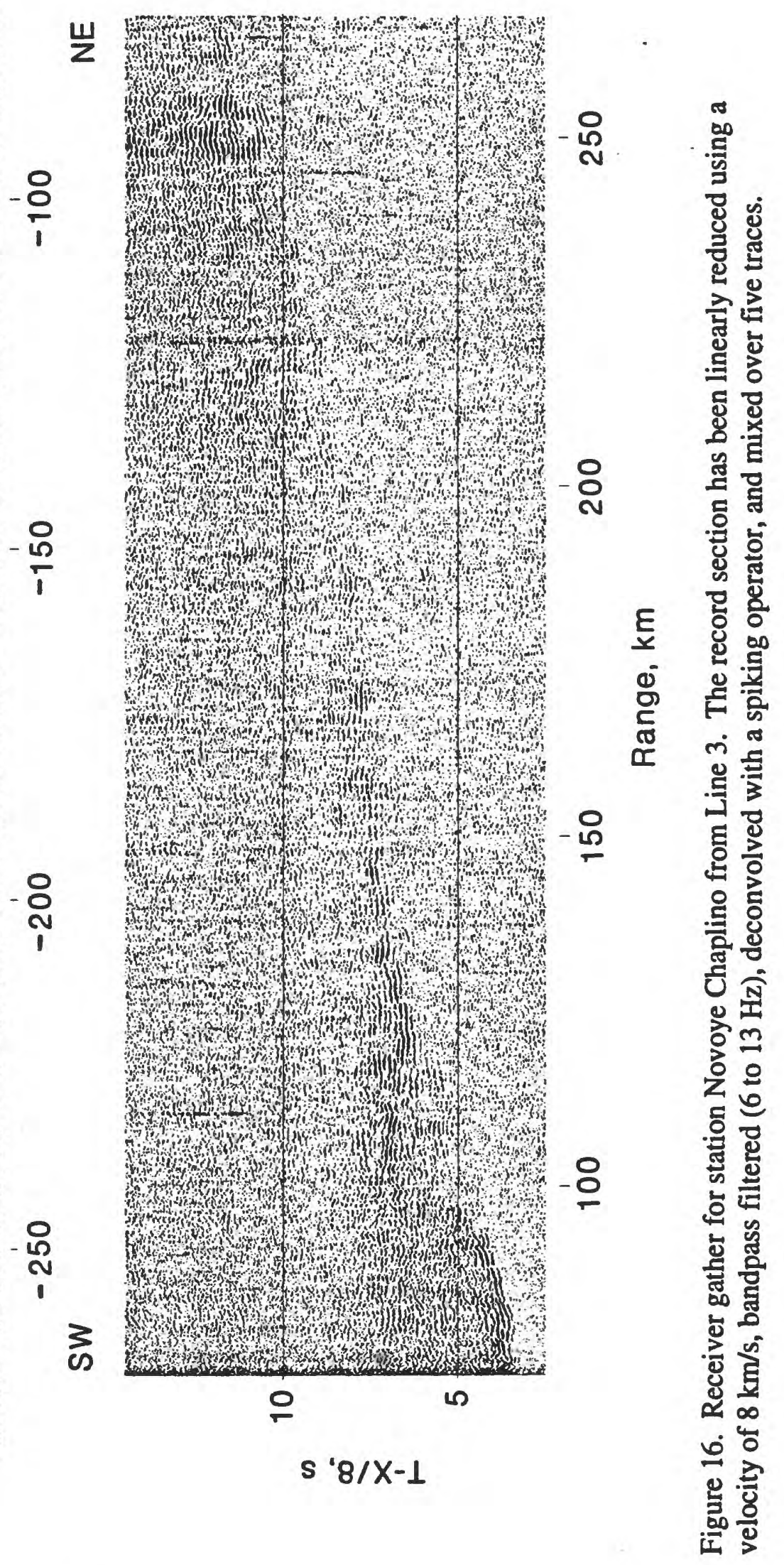




\section{崖}

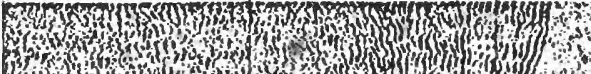

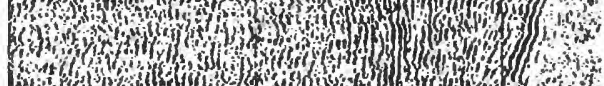

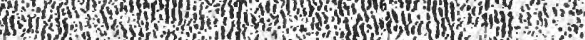

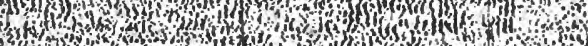

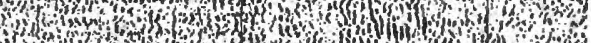

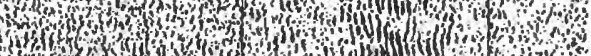
W $30 \mathrm{c}$ (1)

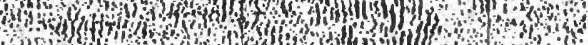

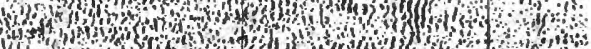

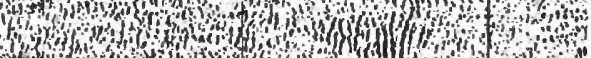

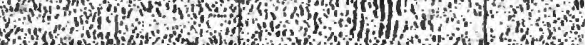

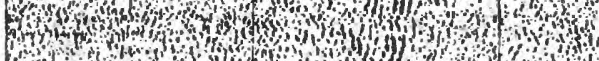

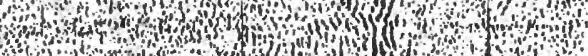

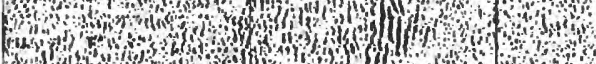

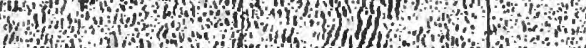

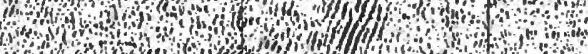

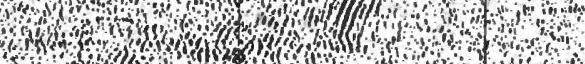

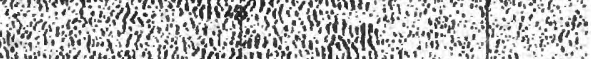

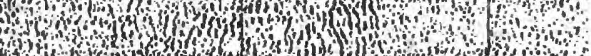

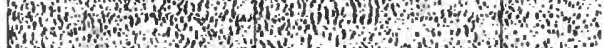

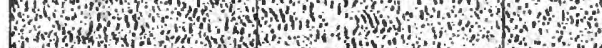

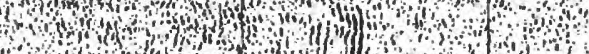

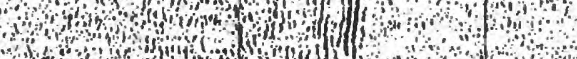

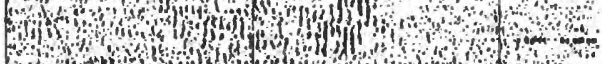

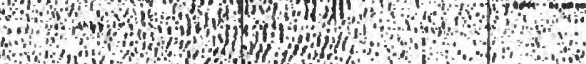

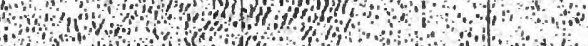
mow whom

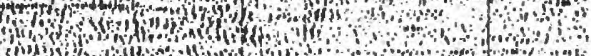

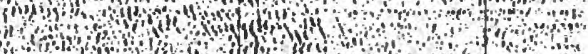

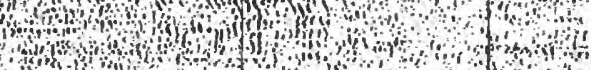

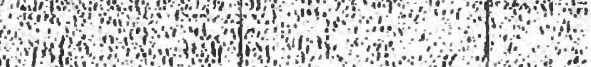

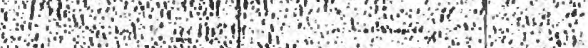

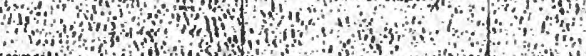

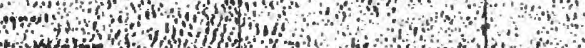

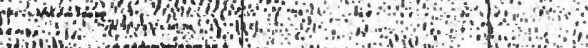

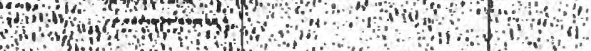

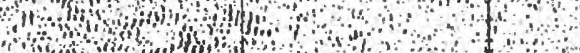

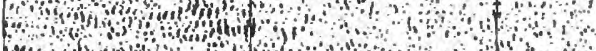
How

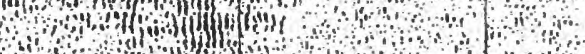
mon of का inis ind

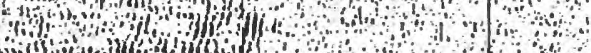

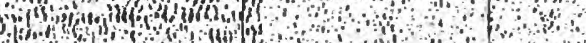

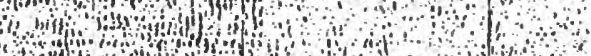
ond of

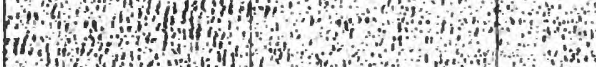
of

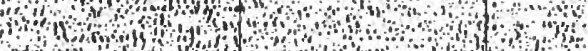

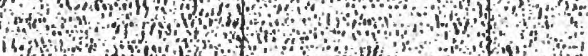

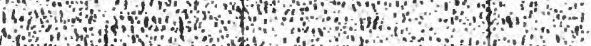
on w o w w w

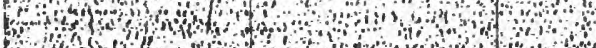

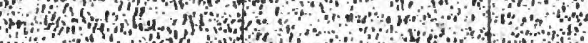

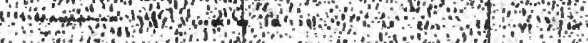

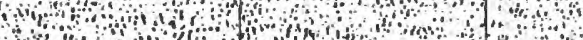

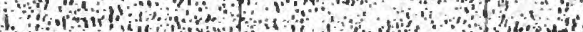

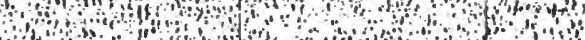

3 mong on

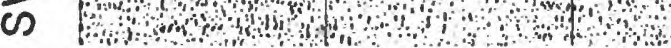
18

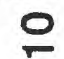
is

$5 \cdot 8 / x-1$

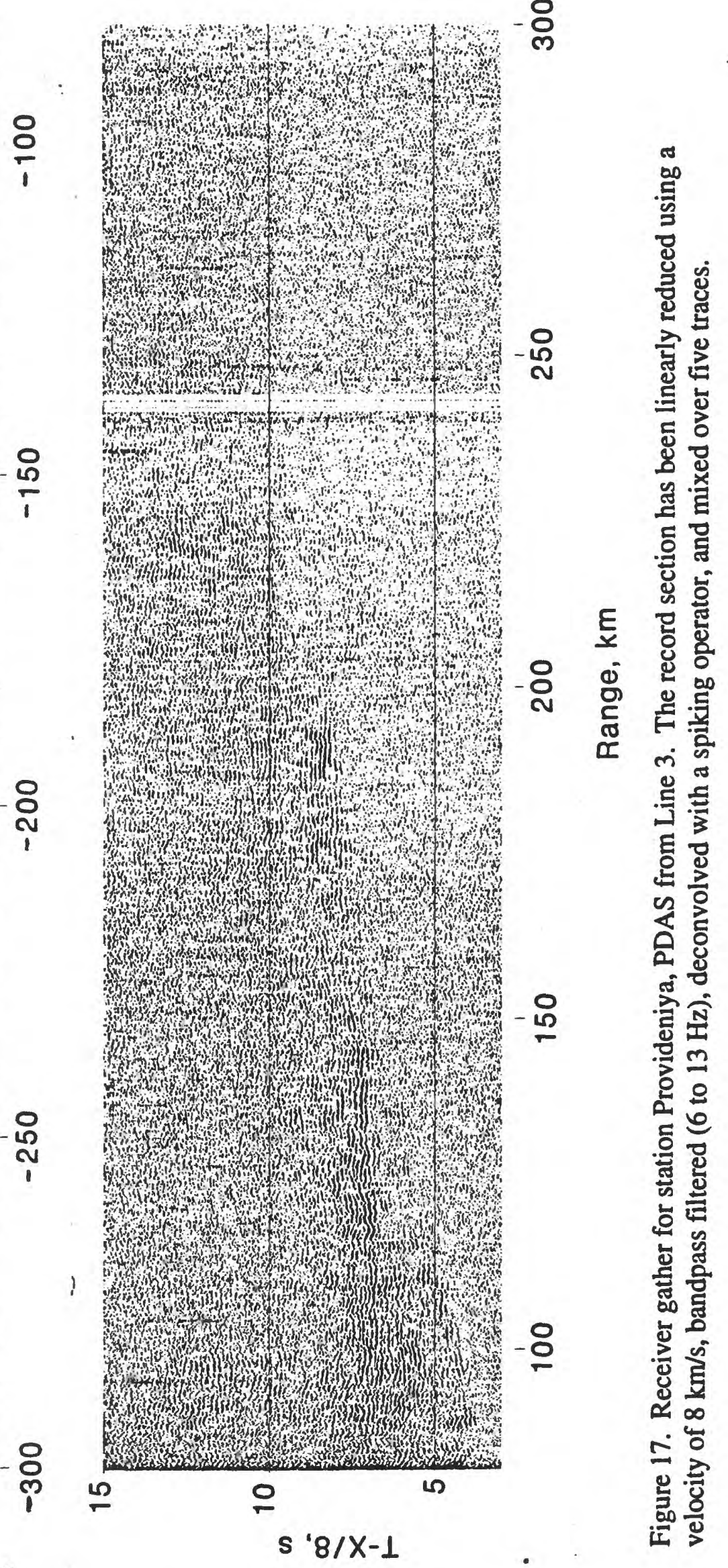



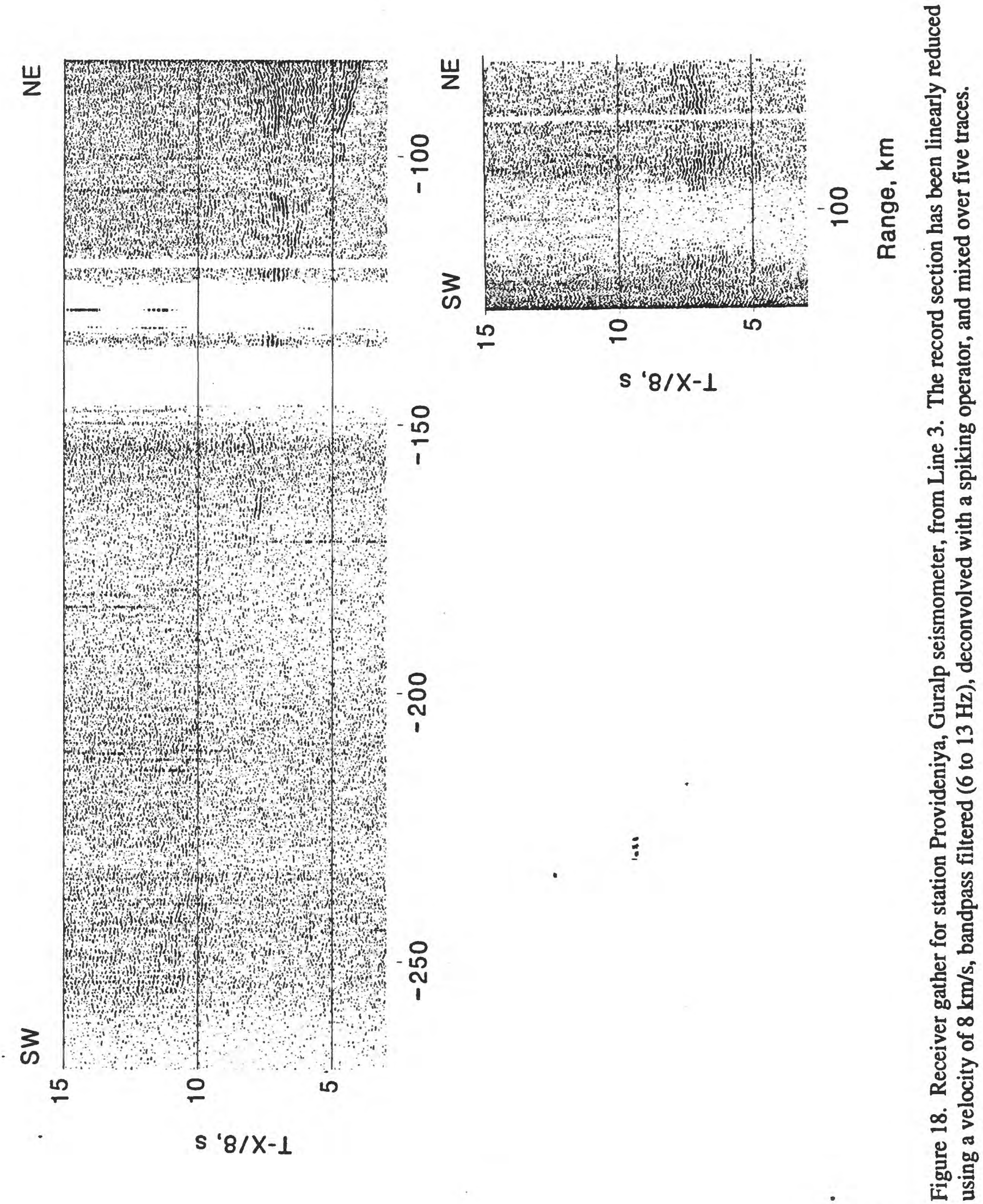

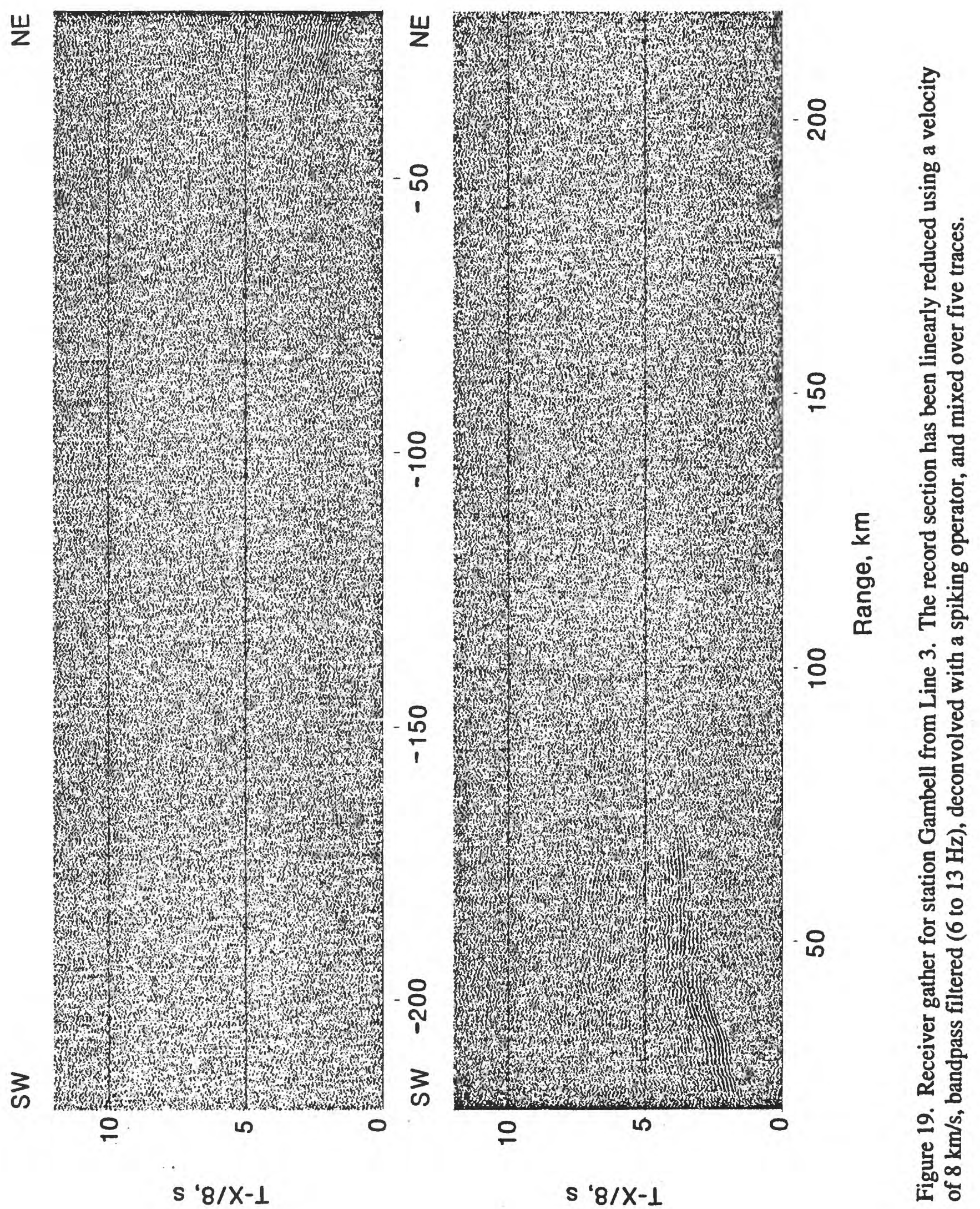


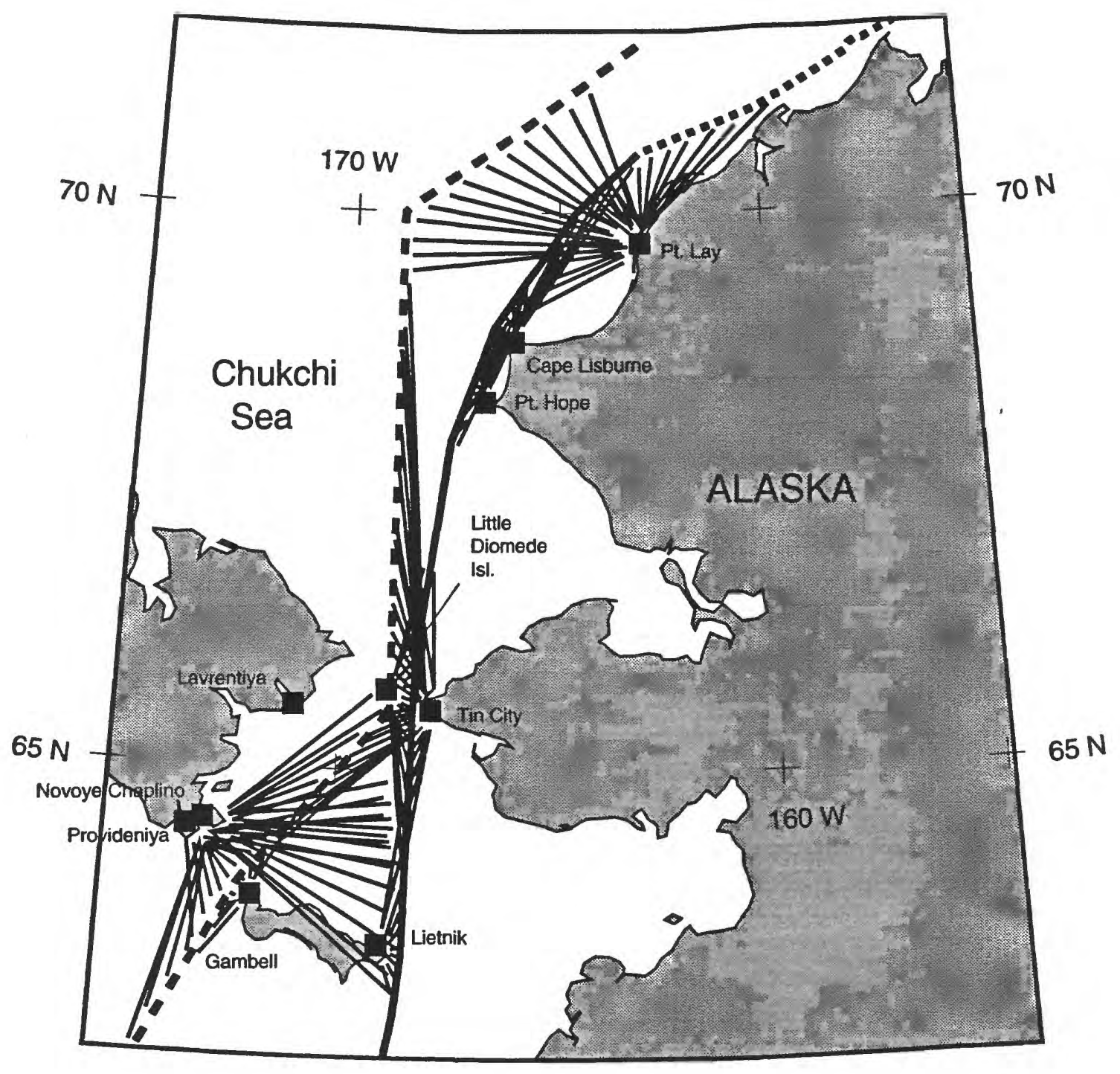

Figure 20. Detail of location map showing ray coverage provided by recorded data. 


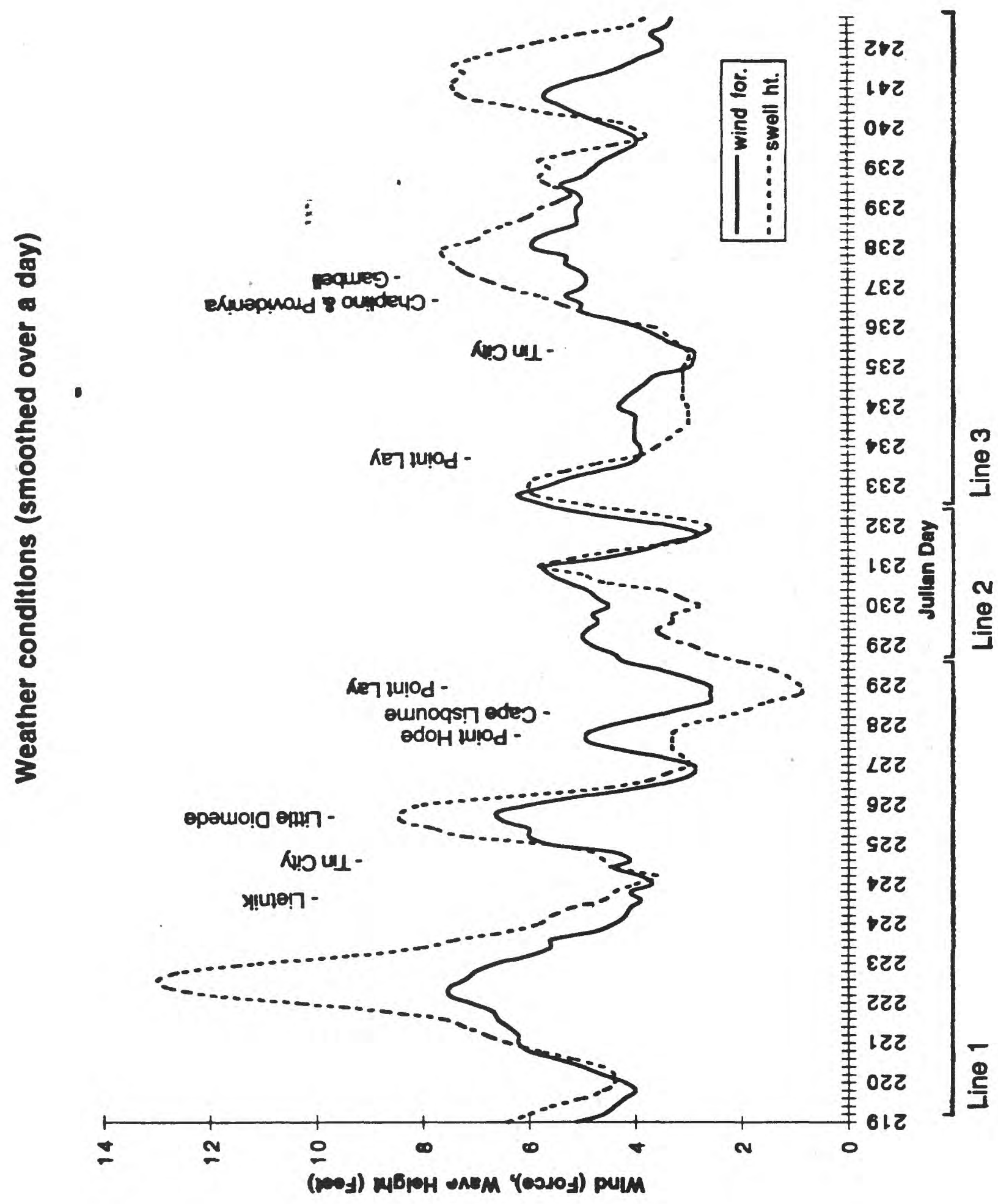

